\title{
An Evaluation of the GOES-16 Rapid Scan for Nowcasting in Southeastern Brazil: Analysis of a Severe Hailstorm Case
}

\author{
Bruno Z. Ribeiro, luiz A. T. Machado, Joao H. Huamán Ch., and Thiago S. Biscaro \\ Centro de Previsão de Tempo e Estudos Climáticos, Instituto Nacional de Pesquisas Espaciais, Cachoeira Paulista, São Paulo, Brazil \\ EDMILSON D. FREITAS \\ Instituto de Astronomia, Geofísica e Ciências Atmosféricas, Universidade de São Paulo, São Paulo, Brazil \\ KATHRYN W. MOZER \\ NOAA/NESDIS/Office of Satellite and Product Operations, College Park, Maryland \\ STEVEN J. GOODMAN \\ GOES-R Program/TGA, Huntsville, Alabama
}

(Manuscript received 28 March 2019, in final form 21 August 2019)

\begin{abstract}
The GOES-16 mesoscale domain sector (MDS) scans with 1-min intervals are used in this study to analyze a severe thunderstorm case that occurred in southeastern Brazil. The main objective is to evaluate the GOES-16 MDS rapid scans against the operational full-disk scans with lower temporal resolution for nowcasting. Data from a C-band radar, observed sounding, and a ground-based lightning network are also used in the analysis. A group of thunderstorms formed in the afternoon of 29 November 2017 in an environment of moderate convective available potential energy (CAPE) and deep-layer shear. The storms presented supercell characteristics and intense lightning activity with peak rates in excess of 150 flashes per 5 min. The satellite-derived trends with 1-min interval were skillful in detecting thunderstorm intensification, mainly in the developing stage. The decrease in cloud-top $10.35-\mu \mathrm{m}$ brightness temperature was accompanied by increases in ice mass flux, concentration of small ice particles at cloud top, and storm depth. In the mature stage, there is no evident trend in the satellite-derived parameters that could indicate storm intensification, but the cluster area expands suggesting cloud-top divergence. The 1-min rapid scans indicate greater lead time to severe weather relative to 10- and 15-min-resolution imagery, but also presented numerous false alarms (indication of severe weather but no occurrence) due to oscillations in the satellitederived parameters. The parameters calculated every 5 min presented better skill than 10 and 15 min and fewer false alarms than $1 \mathrm{~min}$.
\end{abstract}

\section{Introduction}

Nowcasting using satellites entered a new era with the new generation of the National Oceanic and Atmospheric Administration (NOAA) Geostationary Operational Environmental Satellite-R (GOES-R) Series. The GOES-R Series provide geostationary data with unprecedented spatial, temporal, and radiometric resolutions over South America with the Advanced Baseline Imager (ABI), as well as lightning data through the Geostationary Lightning Mapper (GLM),

Corresponding author: Bruno Z. Ribeiro, bruno.ribeiro@inpe.br and they are especially useful for nowcasting in regions with sparse radar coverage (Schmit et al. 2017). Of particular interest for nowcasting purposes is the GOES-R Series ABI mesoscale domain sector (MDS) that provides rapid scanning with a temporal resolution of $1 \mathrm{~min}$ or $30 \mathrm{~s}$ over a movable domain of approximately $1000 \mathrm{~km} \times 1000 \mathrm{~km}$ that can be executed anywhere in the satellite field of view (Schmit et al. 2015). This study focuses on a severe thunderstorm case in Brazil using 1-min MDS scans.

The benefits of satellite scans with high temporal resolution $(<5$-min interval) for monitoring thunderstorms are explored in several studies (e.g., Dworak et al. 2012; 
Bedka et al. 2015; Mecikalski et al. 2016; Apke et al. 2016; Line et al. 2016). Severe thunderstorms with strong updrafts can evolve more rapidly than the trends revealed in operational 15-min full-disk scans (Bedka et al. 2015; Cintineo et al. 2013), so that higher scanning temporal resolution can improve the accuracy of nowcasting techniques and forecaster situational awareness and increase the lead time (the time between a given parameter trend that indicates severe weather is likely and when the severe weather is observed at surface) of severe thunderstorm warnings. As an example, Goodman et al. (1988) studied a severe thunderstorm that evolved from no lightning to maximum lightning activity in 7-8 min and caused a microburst with small pea-sized hail at the ground 4 min after peak lightning activity. Such rapid storm evolutions are not possible to monitor with scans every $15 \mathrm{~min}$ (Gatlin and Goodman 2010).

Given that severe thunderstorms can evolve very rapidly, several techniques based on satellite products were developed to identify convective initiation and thunderstorm intensification (e.g., Mecikalski and Bedka 2006; Mecikalski et al. 2010a,b). Algorithms based on 15-min resolution are useful for forecasters to identify the thunderstorm characteristics. For example, the updraft trend can be estimated by the rate of decrease of the cloud-top temperature (e.g., Mecikalski et al. 2016) and the cloud-top glaciation can be evaluated by using the trispectral difference (e.g., Ackerman et al. 1990; Strabala et al. 1994). The physical properties of the thunderstorms as estimated by satellites can be used to predict the occurrence of severe weather. Even though these algorithms are valuable when using 15-min satellite data, several studies show that higher temporal resolution can provide greater lead time to severe weather when issuing a warning (e.g., Bedka et al. 2015; Bedka and Khlopenkov 2016). The present study aims at comparing satellite-derived parameters with different temporal resolutions to evaluate the different lead times to severe weather and the advantages of using the MDS scanning for severe subtropical storms over South America.

Several studies have used the GOES data to study convection over South America (e.g., Machado et al. 1998; Vila et al. 2008; Durkee and Mote 2010). Most of these studies focus on the climatological aspects of mesoscale convective systems (Machado et al. 1998; Durkee and Mote 2010) and extrapolation techniques to forecast convective systems' motion (Vila et al. 2008). Due to the absence of rapid scans over South America, no study has focused on the advantages of using these data in nowcasting in this continent. Even though the use of satellite data is one of the many tools used in severe thunderstorm monitoring, in some regions of South America they are the only spatial data available in real time.

During the testing period of the first GOES-R Series satellite (now the operational GOES-16 or GOES East), a 1-min MDS was made available over southeastern Brazil on 28 and 29 November 2018 to support the System for Observing and Forecasting Severe Weather (SOS-CHUVA, acronym in Portuguese; Machado et al. 2014) field campaign intense observation period (IOP). The occurrence of severe storms within the GOES-16 MDS, the ground lightning network, and C-band radar coverage generated an unprecedented opportunity to study severe thunderstorms in Brazil.

In this study, the GOES-16 1-min MDS data are used to analyze two severe hailstorms in southeastern Brazil and evaluate the benefits of rapid scans relative to the formerly available operational scans with $10-30 \mathrm{~min}$ of frequency. The main scientific questions raised in this study are: What are the main differences between the severe storms that occurred in the region in terms of cloud-top microphysical characteristics as inferred by satellite and lightning activity? Do the satellitederived parameters in severe subtropical storms behave similarly to midlatitude storms previously studied in other regions of the world? Do the 1-min data provide a significant gain in the nowcasting lead time to severe weather relative to scans with lower temporal resolution for the studied case?

This paper is organized as follows: section 2 describes the data and methodology; section 3 shows the results, which are divided in the analysis of the preconvective environment (section 3a), convective initiation and storm evolution (section $3 \mathrm{~b}$ ), the temporal variations of the satellite-derived parameters and their use in nowcasting (section 3c), and an evaluation of satellite parameters with different temporal frequencies (section 3d). The conclusions are presented and discussed in section 4 .

\section{Data and methodology}

\section{a. The SOS-CHUVA campaign}

The SOS-CHUVA campaign IOP was held from 27 to 31 November 2017 in southeastern Brazil. During this period, the area of the experiment in southeastern Brazil was sampled by radars, disdrometers, radiosondes, surface stations, hailpads, and the GOES-16 was performing MDS scans with 1-min intervals over the SOS-CHUVA area and nearby (Fig. 1) on 28 and 29 November 2017. The storms in this study were too far from the SOS-CHUVA ground based observation network to utilize that data, but the 29 November 


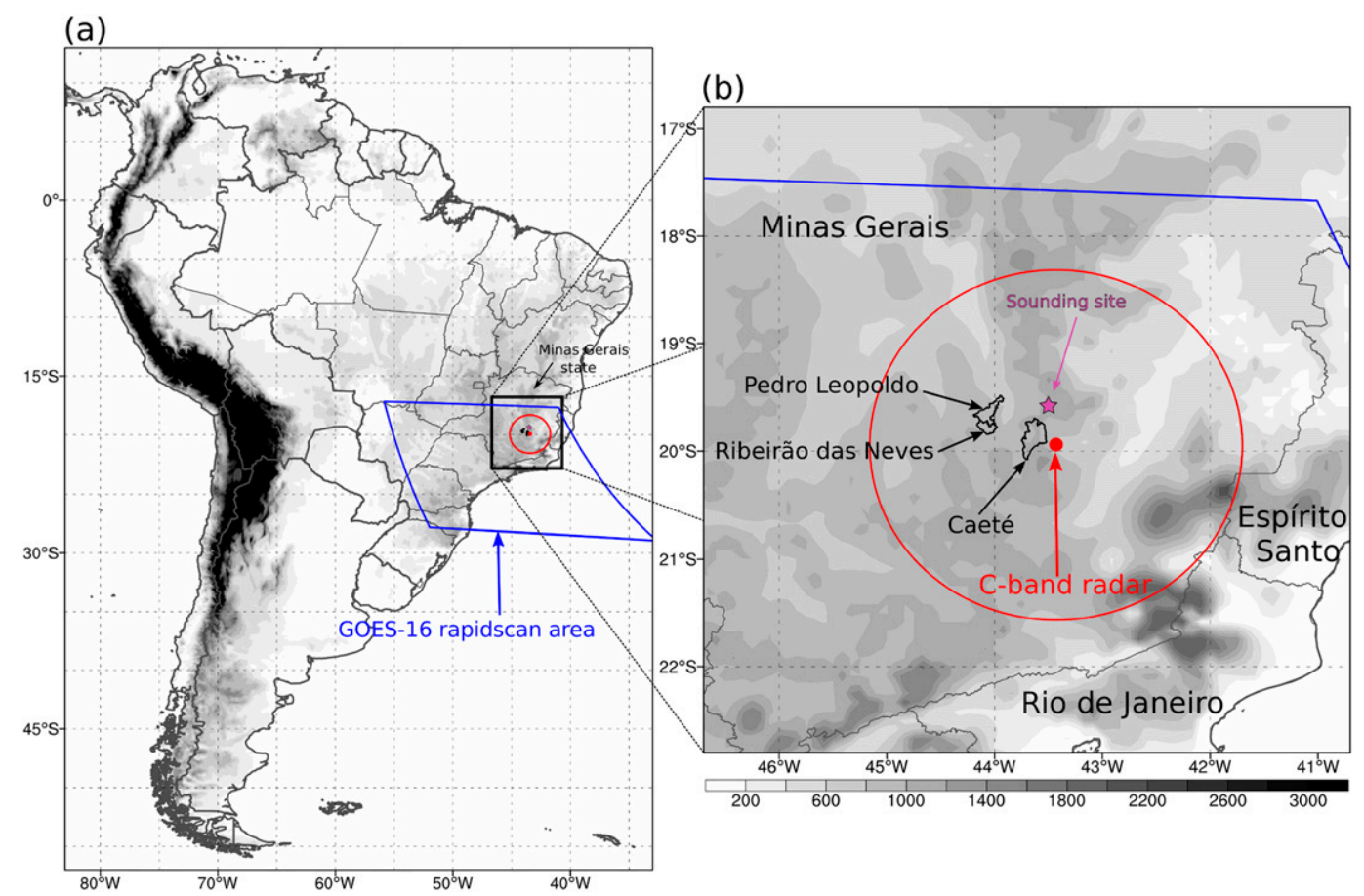

FIG. 1. Map showing the study region in the Minas Gerais state, southeastern Brazil, and the areas of the affected counties (Caeté, Ribeirão das Neves, and Pedro Leopoldo). The GOES-16 rapid scan area during 29 Nov 2017 is delimited by the blue polygon. The red dot is the location of the Mateus Leme C-band radar $\left(19.94^{\circ} \mathrm{S}, 43.43^{\circ} \mathrm{W}, 1270-\mathrm{m}\right.$ altitude), and the red circle is the area covered by the radar ( $250-\mathrm{km}$ radius). The magenta star is the location of the SBCF sounding site. The state of Minas Gerais in southeastern Brazil is also indicated.

2017 MDS data allowed for an extensive satellite analysis of the storms.

\section{b. GOES-16 data and satellite-derived parameters}

The GOES-16 ABI (Schmit et al. 2017) channels employed were the $1.6-\mu \mathrm{m}$ band with $1-\mathrm{km}$ spatial resolution and the bands $6.19,8.5,10.35,11.2$, and $12.3 \mu \mathrm{m}$ with $2-\mathrm{km}$ spatial resolution, with all data in the original satellite projection. The satellite was in the postlaunch testing period at $89.5^{\circ} \mathrm{W}$, west of its operational position $\left(75.2^{\circ} \mathrm{W}\right)$. The cloud properties (level 2) had not yet been provisionally validated for operational use, thus only the different ABI channels were used in this study.

A clustering method was applied to the GOES-16 data to identify convective systems and calculate the Lagrangian satellite-derived parameters. The method is based on the ForTraCC (Vila et al. 2008), in which a cluster is defined as a continuous area of at least 40 pixels with $10.35-\mu \mathrm{m}$ brightness temperature $(\mathrm{Tb})$ lower than $235 \mathrm{~K}$. By using the tracking algorithm, it was possible to compute the cloud cluster size and temporal evolution (Machado and Laurent 2004), and the cloud-top Tb in different channels (Mecikalski et al. 2010a,b). Table 1 shows a summary of each satellite-derived parameter with the respective critical values used for monitoring deep convection. In this study, we used the minimum or maximum value of the parameter in the cluster to evaluate the temporal trends, since extreme values are generally related to the strongest convective updrafts. The parameters were calculated with intervals of $1,5,10$, and $15 \mathrm{~min}$.

One of the main variables used to estimate the convective cloud depth is the $10.35-\mu \mathrm{m} \mathrm{Tb}$. Lower $\mathrm{Tb}$ relates to deeper cloud tops simply because the temperature decreases with height in the troposphere (Adler and Mack 1986). The updraft strength can be estimated by the temporal derivative of the $10.35-\mu \mathrm{m}$ Tb (Adler and Fenn 1979; Roberts and Rutledge 2003; Mecikalski and Bedka 2006). In general, cloudtop cooling rates greater than $4 \mathrm{~K}$ in $15 \mathrm{~min}$ indicate a convective updraft, while cooling rates of $8 \mathrm{~K}$ in $15 \mathrm{~min}$ are associated with a vigorous updraft (Mecikalski and Bedka 2006). The difference between 6.19- and 10.35- $\mu \mathrm{m}$ $\mathrm{Tb}$ also provides estimates of the cloud depth. Negative values are associated with clear regions or shallow clouds, while in cases of deep convection, when the cloud tops reach the tropopause or lower 
TABLE 1. Interest fields and critical values.

\begin{tabular}{lll}
\hline \hline \multicolumn{1}{c}{ Physical attribute } & \multicolumn{1}{c}{ Interest field } & \multicolumn{1}{c}{ Critical values } \\
\hline Particle size & $1.6-\mu \mathrm{m}$ reflectance & $\begin{array}{l}\text { Low values } \rightarrow \text { large particles size } \\
\text { High values } \rightarrow \text { small particles size }\end{array}$ \\
& $8.5-\mu \mathrm{m} \mathrm{Tb}-11.2-\mu \mathrm{m} \mathrm{Tb}$ & $\begin{array}{l}\text { High positive values } \rightarrow \text { small ice crystals } \\
\text { Low positive values } \rightarrow \text { large ice crystals } \\
\end{array}$ \\
Cloud-top glaciation/ice mass flux & $(8.5-11.2-\mu \mathrm{m} \mathrm{Tb})-(11.2-12.3-\mu \mathrm{m} \mathrm{Tb})$ & $>0 \rightarrow$ ice crystals \\
& & $<0 \rightarrow$ water droplets \\
Cloud depth & $6.19-\mu \mathrm{m} \mathrm{Tb}-10.35-\mu \mathrm{m} \mathrm{Tb}$ & $>-10 \mathrm{~K} \rightarrow$ deep cloud \\
& $10.35-\mu \mathrm{m} \mathrm{Tb}$ & $\mathrm{Tb}<273 \mathrm{~K} \rightarrow$ deep cloud \\
Updraft strength & Temporal derivative of $10.35-\mu \mathrm{m} \mathrm{Tb}$ & $d \mathrm{~Tb} / d t<-4 \mathrm{~K}(15 \mathrm{~min})^{-1} \rightarrow$ updraft \\
& & $d \mathrm{~Tb} / d t<-8 \mathrm{~K}(15 \mathrm{~min})^{-1} \rightarrow$ vigorous updraft \\
\hline
\end{tabular}

stratosphere, the $6.19-10.35-\mu \mathrm{m}$ difference is positive (Fritz and Laszlo 1993; Ackerman 1996; Schmetz et al. 1997; Mecikalski and Bedka 2006; Machado et al. 2009).

The cloud-top particle size is estimated using the $1.6-\mu \mathrm{m}$ band reflectance, which associates lower reflectance values with larger particle size and vice versa (Baum et al. 2000). An increase in the 1.6- $\mu \mathrm{m}$ band reflectance for cloud-top temperatures above $233 \mathrm{~K}$ is also linked to glaciation. The reflectance values of this band were obtained by converting the reflectance factor to reflectance using $1 / \cos (\theta)$, where $\theta$ is the solar zenith angle. In this case, due to the fact that reflectance values become undefined with solar zenith angles near $90^{\circ}$ (Lindsey et al. 2006), only times before 1950 UTC were considered in this study, when the zenith angle is nearly $72^{\circ}$ in this location. The difference between 8.5 and $11.2 \mu \mathrm{m}$ is used to monitor cloud-top ice crystal sizes as well. This difference is positive in cloud tops containing ice crystals. High positive values are associated with smaller ice crystals and low positive values with larger ice crystals (Ackerman et al. 1990).

Cloud-top glaciation and variations in ice mass flux are inferred by using the trispectral difference (Ackerman et al. 1990; Strabala et al. 1994), which is based on the different values of water and ice absorption coefficients in the 8.5-12.3- $\mu \mathrm{m}$ range. Positive values of the trispectral difference $[(8.5-11.2 \mu \mathrm{m})-(11.2-12.3 \mu \mathrm{m})]$ can be attributed to ice crystals and negative values to water droplets.

\section{c. Other datasets}

Data from the C-band radar located in Mateus Leme (19.94 ${ }^{\circ} \mathrm{S}, 43.43^{\circ} \mathrm{W}, 1270$-m altitude; Fig. $\left.1 \mathrm{~b}\right)$ were also used. The radar has a beamwidth of $1^{\circ}$, radial resolution of $250 \mathrm{~m}$, wavelength of $5.328 \mathrm{~cm}$, and generates a volume scan with 10 elevations every $5 \mathrm{~min}$. This radar is operated by the Companhia Energética de Minas Gerais (CEMIG). Unfortunately, polarimetric variables and radial winds data were very noisy in the studied period, thus only the reflectivity is used in this study. The two storms were tracked using the $0.5^{\circ}$ plan position indicator (PPI) horizontal reflectivity factor with the reflectivity threshold of $40 \mathrm{dBZ}$ to define a storm cluster. The centroid of the reflectivity core is used as a proxy for the storm location, which allowed for tracking the position of the storm every $5 \mathrm{~min}$ (frequency of radar scans), generating a radar-derived trajectory for each storm. The maximum reflectivity and average vertically integrated liquid (VIL) are also calculated every $5 \mathrm{~min}$ for each storm cluster.

The lightning data used in this study derive from the Brazilian Lightning Detection System [Sistema Brasileiro de Detecção de Descargas Atmosféricas (BrasilDAT)] network, which encompasses more than 70 lightning sensors (Earth Networks). The BrasilDAT detection efficiency is greater than $90 \%$ (for both intracloud and cloud-to-ground lightning flashes) over southeastern Brazil (Naccarato and Pinto 2009). The total lightning (sum of cloud-to-ground and cloud-tocloud lightnings) was used in this study because this quantity is physically related to storm/updraft intensity and provides greater skill in nowcasting than the use of cloud-to-ground lightning alone (e.g., Schultz et al. 2009; Wu et al. 2018). The lightning strikes occurred within $10 \mathrm{~km}$ from the pixel with minimum $10.35-\mu \mathrm{m} \mathrm{Tb}$ of the cluster in each 1-min interval were manually associated with each storm, and lightning density refers to the number of strikes associated with the storm accumulated in 5-min intervals. Since the GLM sensor was being tested during this period, we decided to use only BrasilDAT data.

The convective environment was accessed using the Global Forecast System [GFS, from the National Centers for Environmental Prediction (NCEP)] model analysis. The GFS is a T1534 global model with 64 vertical levels starting a new integration every $6 \mathrm{~h}$. The model output is interpolated to a $0.25^{\circ}$-resolution grid, which is used in this study. Sounding data of the Confins Airport (SBCF; $19.62^{\circ} \mathrm{S}, 43.67^{\circ} \mathrm{W}$; Fig. 1) 


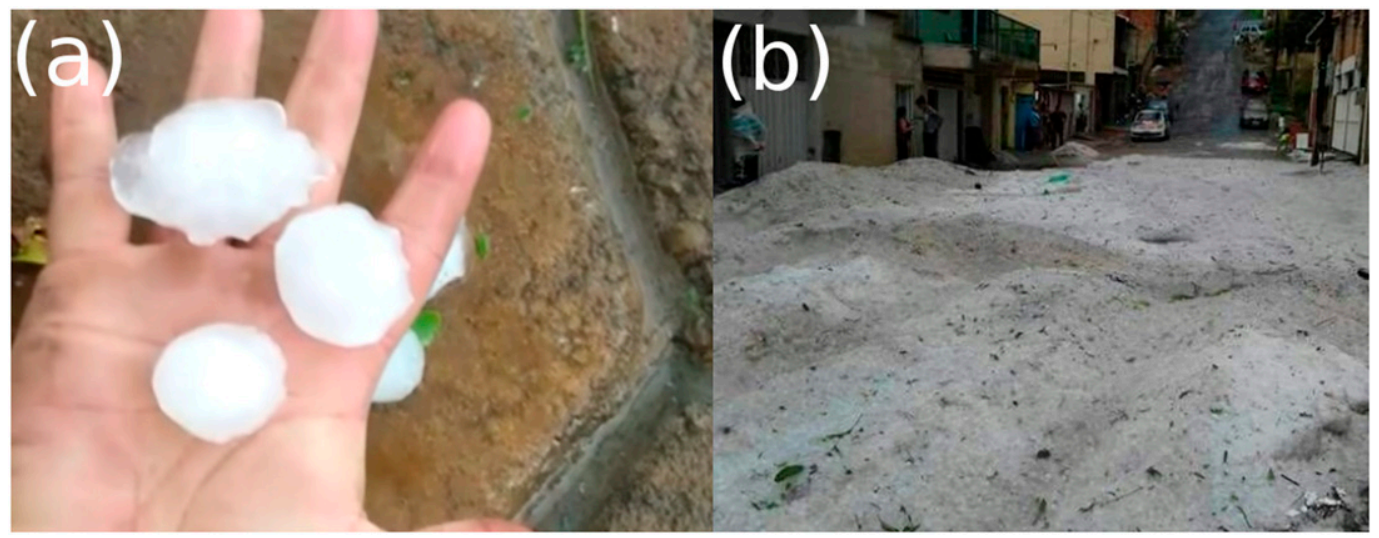

FIG. 2. Photos of the hailstones and associated damage on 29 Nov 2017. Shown are (a) 4-5-cm hailstones in Caeté and (b) hail accumulation in a street of Pedro Leopoldo.

were taken from the University of Wyoming website (University of Wyoming 2017).

\section{Results}

On the afternoon of 29 November 2017, severe storms occurred in east-central Minas Gerais state (Fig. 1) and caused severe winds and large hail (Fig. 2). In the city of Caeté, hail of nearly $5 \mathrm{~cm}$ in diameter was responsible for widespread damage to buildings and vehicles (Fig. 2a). According to the local Civil Defense, 14 people were injured, more than 300 had to leave their homes, and 2050 buildings were damaged. The cities of Ribeirão das Neves and Pedro Leopoldo, located approximately 100 and $120 \mathrm{~km}$, respectively, to the northwest of Caeté (Fig. 1b), were affected by another storm nearly two hours after Caeté (Fig. 2b). Pedro Leopoldo reported 5-cm hail, whereas severe winds and 2-cm hail occurred in Ribeirão das Neves, producing damage to roofs and trees in both cities. The storms in the region occurred between 1630 and 2100 UTC. No severe weather reports were associated with the other storms in the region on this day. This study focuses only on the two storms that were confirmed as severe.

\section{a. Preconvective environment}

Figure 3 shows the GFS analysis fields at 1800 UTC 29 November 2017, when convective activity was increasing in the region. A broad cyclonic circulation is observed over the Atlantic Ocean with attendant cyclonic vorticity maximum near the coast of Brazil (Fig. 3a). Minas Gerais state is in the northwestern periphery of the cyclonic circulation, where southwesterly flow predominates. There is no cyclonic vorticity maximum upstream of the region. A $500-\mathrm{hPa}$ temperature trough is over the affected cities at this time with $500-\mathrm{hPa}$ temperatures of nearly $-9^{\circ} \mathrm{C}$. Relatively cold air in the midtroposphere is known to favor hail growth (e.g., Johnson and Sugden 2014). The strongest $500-\mathrm{hPa}$ winds $\left(>15 \mathrm{~m} \mathrm{~s}^{-1}\right)$ occur along the Brazilian coast, where the upper-level jet is located (not shown).

The 850-hPa level 1800 UTC fields are shown in Fig. 3b. A surface cold front moved northeastwards over the Atlantic Ocean on 28 November (one day before; not shown) and stalled along the higher terrain in the coast of Brazil (Fig. 1). Lower 850-hPa equivalent potential temperature $\theta_{e}$ is found over the Atlantic Ocean in association with southeasterly flow, which causes enhanced 1000-700-hPa moisture flux convergence (MFC) along the Brazilian coast. MFC is also observed along a ridge oriented in the south-southwest to north-northeast direction in central Minas Gerais (Fig. 1b), where the three affected cities are located and the $850-\mathrm{hPa} \theta_{e}$ is higher. The MFC along this ridge occurs due to the eastsoutheasterly winds at low levels and serves as a focus for convective initiation after 1600 UTC. These synoptic fields provide evidence that the storms formed under weak synoptic-scale forcing for ascent.

The 1200 UTC 29 November 2017 sounding at SBCF (Fig. 4) depicts a relatively moist air mass between the surface and $\sim 600 \mathrm{hPa}$. The sounding site is no more than $50 \mathrm{~km}$ from the area where the storms occurred. A mixed layer is observed in the first kilometer above the surface indicating the boundary layer mixing due to radiative heating in the beginning of the day (1200 UTC is 0900 local time). Steep temperature lapse rates and lower relative humidity are observed above the $600-\mathrm{hPa}$ level. Even though the most unstable CAPE is only $200 \mathrm{~J} \mathrm{~kg}^{-1}$ at this time, this temperature/dewpoint temperature profile can attain higher instability during the afternoon in response to low-level radiative heating, 

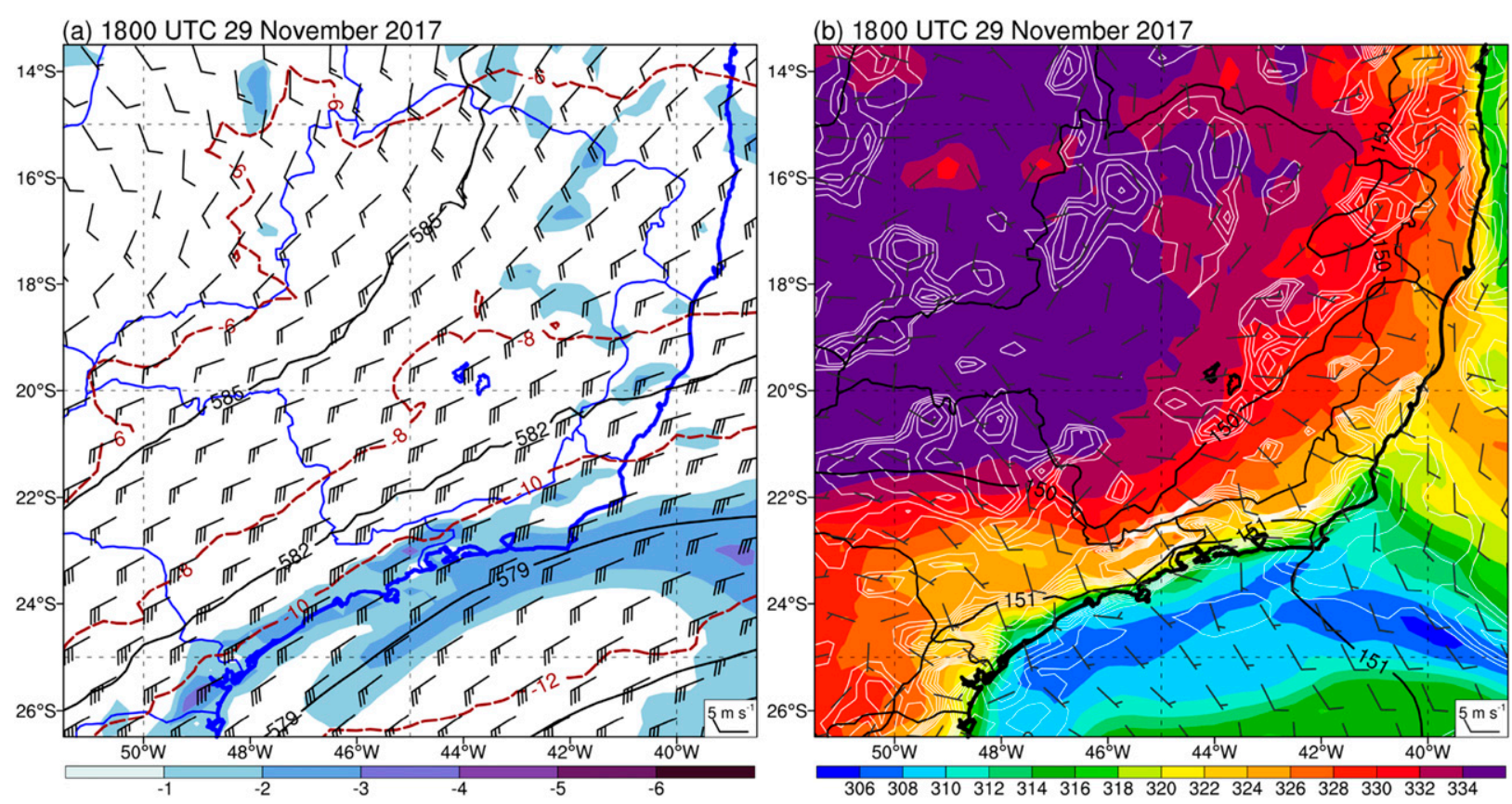

FIG. 3. GFS analysis at 1800 UTC 29 Nov 2017. (a) The $500-\mathrm{hPa}$ relative vorticity $\left(10^{-5} \mathrm{~s}^{-1}\right.$; shaded), temperature $\left({ }^{\circ} \mathrm{C}\right.$; red dashed contours), geopotential height (dam; black continuous contours), and winds ( $\mathrm{m} \mathrm{s}^{-1}$; pennant is $25 \mathrm{~m} \mathrm{~s}^{-1}$, full barb is $5 \mathrm{~m} \mathrm{~s}^{-1}$, and half barb is $2.5 \mathrm{~m} \mathrm{~s}^{-1}$ ). (b) The 850 -hPa $\theta_{e}$ (K; shaded), geopotential height (dam; black contours), and winds ( $\mathrm{m} \mathrm{s}^{-1}$; pennant is $25 \mathrm{~m} \mathrm{~s}^{-1}$, full barb is $5 \mathrm{~m} \mathrm{~s}^{-1}$, and half barb is $\left.2.5 \mathrm{~m} \mathrm{~s}^{-1}\right)$, and $1000-700-\mathrm{hPa}$ MFC $\left(10^{-5} \mathrm{~g} \mathrm{~kg}^{-1} \mathrm{~s}^{-1}\right.$, white contours every $3 \times 10^{-5} \mathrm{~g} \mathrm{~kg}^{-1} \mathrm{~s}^{-1} \mathrm{starting} \mathrm{at}^{-1}$ $\left.3 \times 10^{-5} \mathrm{~g} \mathrm{~kg}^{-1} \mathrm{~s}^{-1}\right)$. Contours of the counties affected by severe weather are drawn.

which corroborates CAPE values of $1189 \mathrm{~J} \mathrm{~kg}^{-1}$ in SBCF at 1800 UTC according to the GFS analysis. The equilibrium level for surface-based parcels is at nearly $180 \mathrm{hPa}$, where the temperature is approximately $-60^{\circ} \mathrm{C}(213 \mathrm{~K})$. Also, the easterly low-level winds turn to southwesterly midlevel winds and cause $0-6-\mathrm{km}$ wind shear of more than $20 \mathrm{~m} \mathrm{~s}^{-1}$, which is sufficient for severe storms with rotating updrafts (e.g., Thompson et al. 2003).

\section{b. Convective initiation and storm evolution}

The estimated time of hailfall in Caeté (Fig. 1b) is 1740 UTC and in Pedro Leopoldo is 1930 UTC. Ribeirão das Neves was affected at nearly 1900 UTC by the same storm that hit Pedro Leopoldo. The hail occurrence time was estimated based on reports of local officials, videos in social media, and radar imagery, and there is an associated error in the estimate of $\pm 5 \mathrm{~min}$. Therefore, we use a 10 -min period centered in the most probable time of hailfall to account for this error. This study focuses on the two severe thunderstorms that produced $5-\mathrm{cm}$ hail in Caeté and Pedro Leopoldo, which are referred to as the Caeté storm (CTS) and Pedro Leopoldo storm (PLS).

Figure 5 shows the evolution of the $10.35-\mu \mathrm{m}$ Tb from 1630 to 2015 UTC every $15 \mathrm{~min}$. The first time the CTS reached $\mathrm{Tb}$ colder than $235 \mathrm{~K}$ is at $1645 \mathrm{UTC}$ (Fig. 5b), which is followed by an increase in the area colder than $235 \mathrm{~K}$ in the next $45 \mathrm{~min}$ (Figs. $5 \mathrm{c}$,d). The coldest $\mathrm{Tb}$ of the entire CTS life time $(212 \mathrm{~K}$ from the 1 -min data at 1736 UTC; Fig. 5e) is attained after the system intensification at 1730 UTC (Fig. 5e), nearly $10 \mathrm{~min}$ before hailfall. The minimum $\mathrm{Tb}$ of CTS is relatively high compared to severe storms documented in the literature (e.g., Bedka et al. 2012, 2015, 2018). Also, there is no V- or U-shape signature (e.g., Setvák et al. 2010, 2013) discernible at the CTS top, but an east-northeastward propagation of the anvil related to high winds aloft. At 1745 UTC (Fig. 5f), the minimum Tb in the CTS cluster is over the city of Caeté. After this time (Figs. $5 \mathrm{~g}-\mathrm{j}$ ), CTS weakens and dissipates at nearly 1900 UTC (Fig. 5k). No severe thunderstorm signature is observed in the satellite imagery [V shape, overshooting top, or above-anvil cirrus cloud (Bedka et al. 2018)] besides the cloud-top cooling.

The PLS forms at nearly 1800 UTC (Fig. $5 \mathrm{~g}$ ) $100 \mathrm{~km}$ west-southwest of CTS. This storm presents a distinct Tb minimum at 1845 and 1900 UTC (Figs. 5j,k), when $2-\mathrm{cm}$ hail and damaging winds were registered in Ribeirão das Neves. A V-shape signature, also indicative of a vigorous updraft, is discernible at 1915 UTC (Fig. 51), nearly $15 \mathrm{~min}$ before the $5-\mathrm{cm}$ hailfall at Pedro Leopoldo. Noticeably, the PLS has minimum 


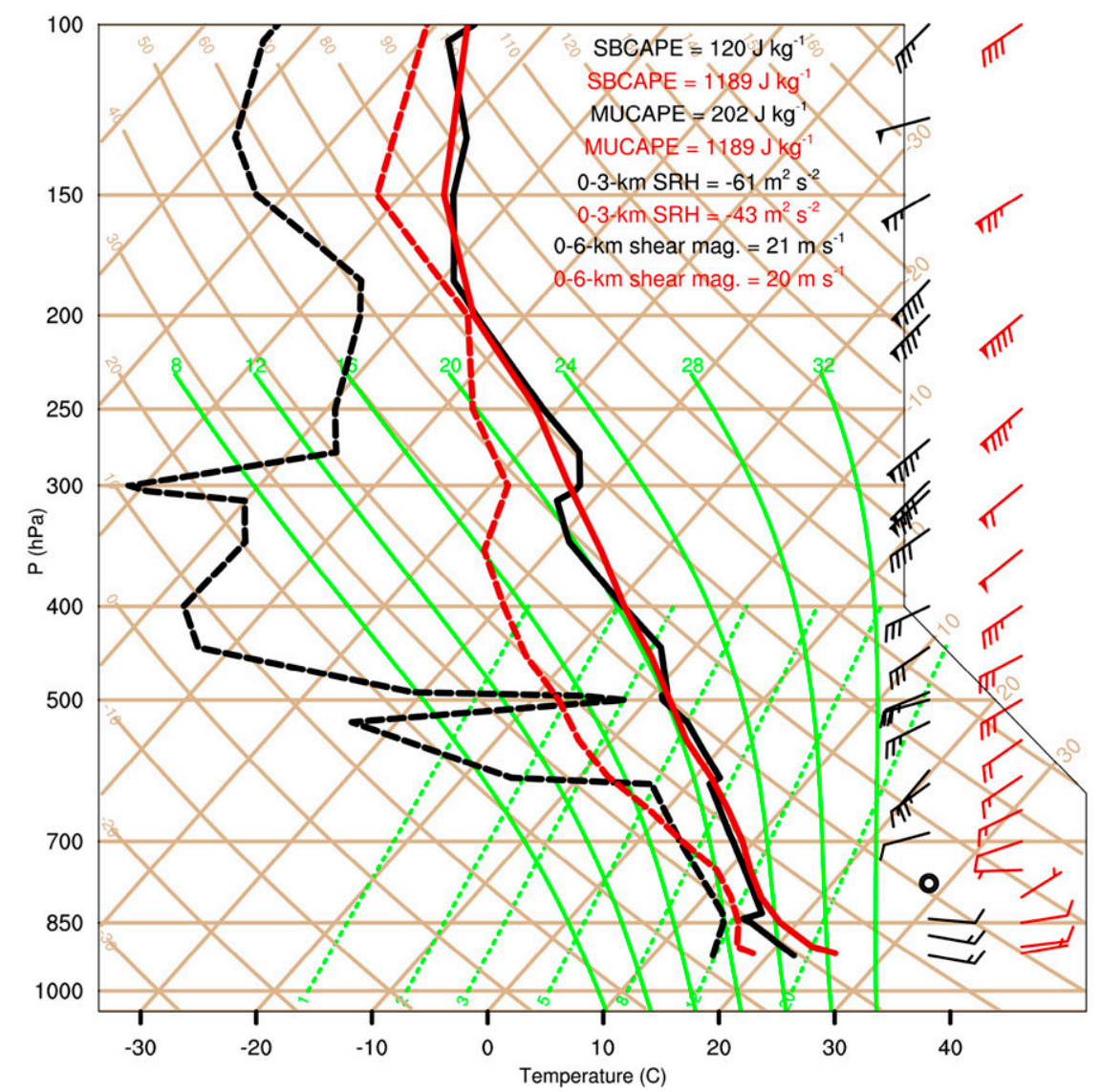

FIG. 4. Skew $T-\log p$ diagram showing the 29 Nov 2017 soundings at Confins Airport $\left(19.62^{\circ} \mathrm{S}\right.$, $43.67^{\circ} \mathrm{W}$; Fig. 1) where the continuous line indicates the temperature and the dashed line the dewpoint temperature. The black sounding and indices correspond to the observed 1200 UTC sounding, while the red sounding and indices correspond to the 1800 UTC sounding at the closest gridpoint using the 1800 UTC GFS analysis. The severe weather parameters calculated with the sounding data are surface-based CAPE (SBCAPE), most unstable CAPE (MUCAPE), 0-3-km storm-relative helicity (SRH), and 0-6-km wind shear magnitude.

Tb of $203 \mathrm{~K}$ at 1946 UTC, nearly 9 K lower than CTS, which indicates a deeper updraft in the PLS storm as compared to CTS. The lower minimum Tb in the PLS cluster is possibly associated with the greater thermodynamic instability (CAPE) in the northern part of the study area and/or rotating, more undiluted updrafts in this storm. Other storms that formed near PLS also had minimum Tb lower than storms that formed in the south of the study region or earlier, such as CTS (not shown). The PLS cluster merges with the other cluster farther south at nearly 1935 UTC.

Imagery every $1 \mathrm{~min}$ allowed the identification of multiple "pulses" of convective intensification and momentary $\mathrm{Tb}$ decrease. A similar behavior was observed in other severe storms (e.g., Apke et al. 2018). Witt et al. (2018), for example, studied the supercell that generated the El Reno, Oklahoma, EF3 tornado on 31 May 2013 and noticed multiple updrafts during a quasi-steady phase of the storm occurred after a period of rapid intensification. The storm was distinguished as a classic supercell after the last of these pulses.

Figure 6 shows CTS and PLS radar-derived trajectories along with total lightning between 1600 and 2100 UTC, and the cluster areas with Tb lower than $235 \mathrm{~K}$ at the estimated time of hail reports (1740 and 1930 UTC, respectively). The radar-derived trajectories and lightning paths clearly show slow storm motion during the first $40 \mathrm{~min}$ of the storms' lifetimes, followed by a leftward turn and acceleration of storm motion. The $0-6-\mathrm{km}$ mean wind derived from the 1800 UTC sounding is shown in Fig. 6 as evidence that the storms were initially advected by the mean wind but then changed the direction of motion, moving to the left of the mean wind. This behavior is a well-known and extensively documented signature of supercells, long-lived storms with a rotating updraft, since the perturbation pressure 

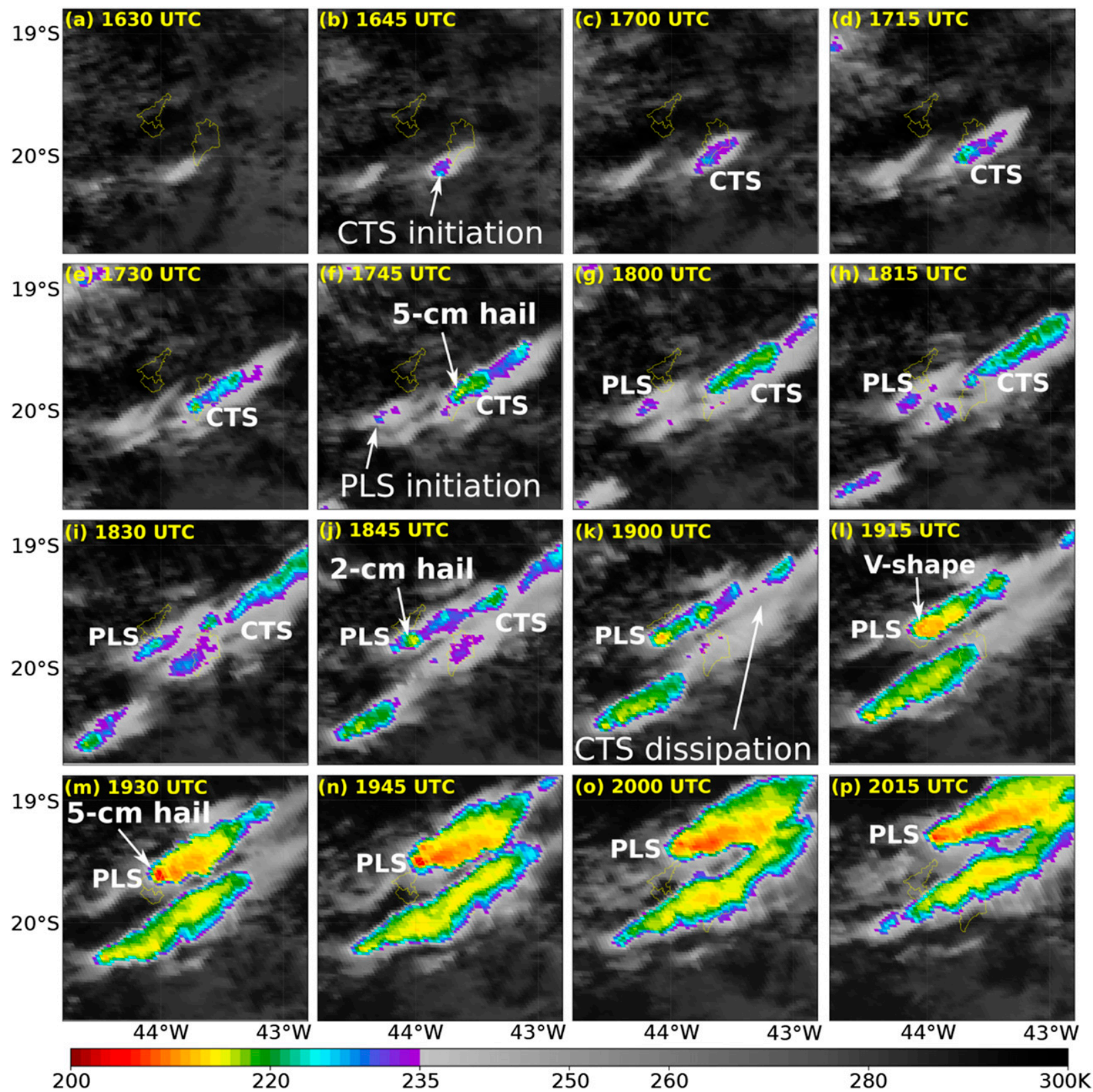

FIG. 5. GOES-16 10.35- $\mu \mathrm{m} \mathrm{Tb}(\mathrm{K})$ at (a) 1630, (b) 1645, (c) 1700, (d) 1715, (e) 1730, (f) 1745, (g) 1800, (h) 1815, (i) 1830, (j) 1845, (k) 1900, (l) 1915, (m) 1930, (n) 1945, (o) 2000, and (p) 2015 UTC. The CTS cluster, PLS cluster, and other noteworthy features are indicated in the figures, as well as the occurrences of hail in each estimated time. All images were displaced to account for the parallax error.

gradient associated with the convective core causes a deflection of the storm motion from the mean wind (Rotunno and Klemp 1982). The individual trajectories of other storms in the region (not shown) followed the $0-6-\mathrm{km}$ mean wind to the east-northeast whereas the supercells moved north-northeastward.

The horizontal reflectivity factor PPIs and vertical cross sections (Fig. 7) also support that the storms were supercells. Hook echoes are observed in low elevation scans at 1730 UTC in CTS (Fig. 7a) and at 1930 UTC in PLS (Fig. 7d). Hook echoes curved to the north are characteristic of cyclonic supercells (left movers) in the Southern Hemisphere (de Lima Nascimento et al. 2014), where the warm/moist storm-relative inflow is from the north. The hook echo signature is distinct in several radar scans of CTS and PLS (not shown). Hail cores with reflectivity greater than $60 \mathrm{dBZ}$ are observed at heights above the $0^{\circ} \mathrm{C}$ isotherm (Figs. $7 \mathrm{~b}, \mathrm{e}$ ). 


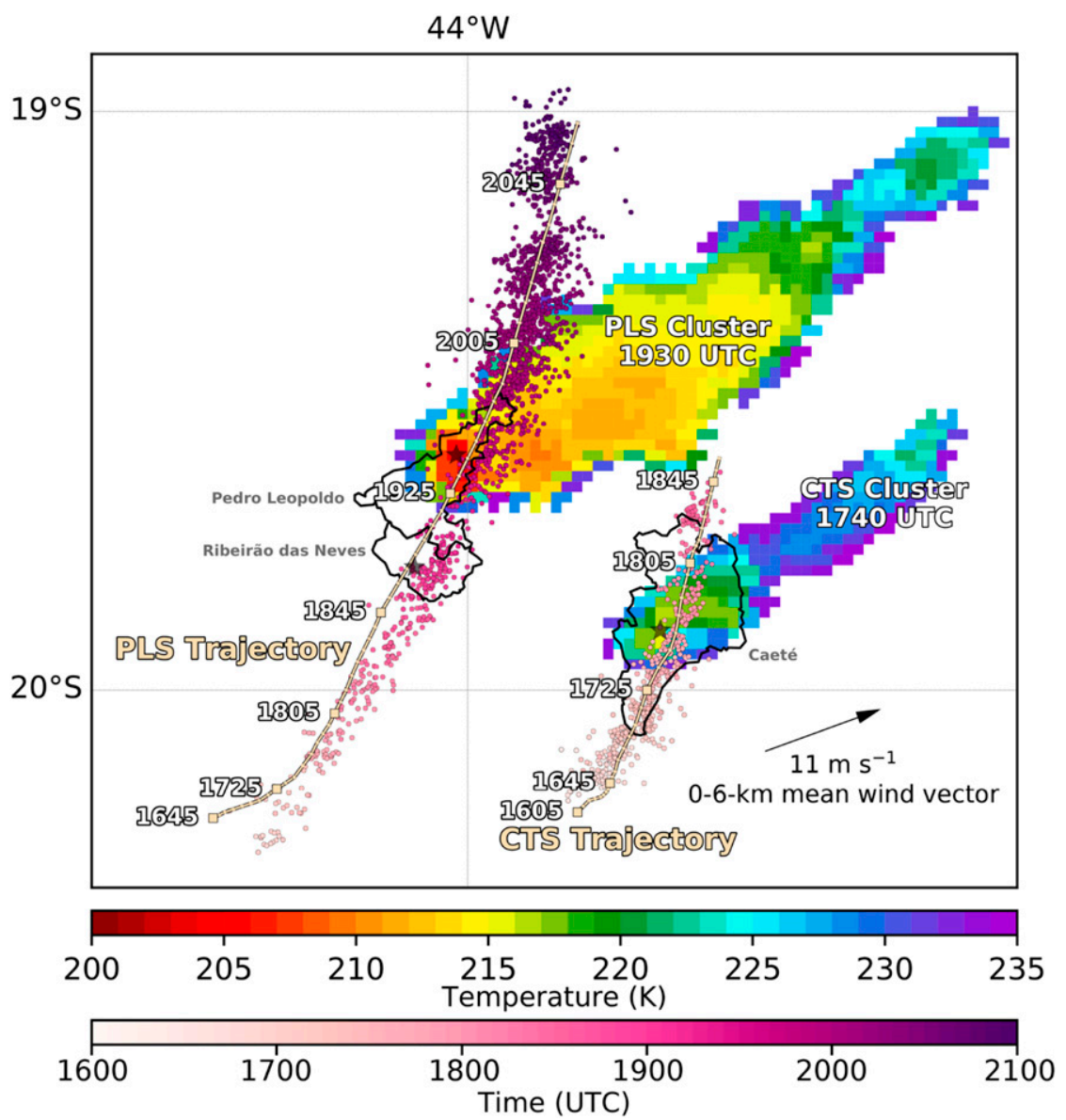

FIG. 6. GOES-16 10.35- $\mu \mathrm{m} \mathrm{Tb}(\mathrm{K}$; shaded) in the CTS and PLS clusters $(\mathrm{Tb}<235 \mathrm{~K})$ at 1740 and 1930 UTC, respectively, BrasilDAT total flashes (magenta dots, accumulated in 5-min intervals according to the color bar), and CTS and PLS trajectories derived from the $0.5^{\circ}$ plan position indicator reflectivity centroids at each $5 \mathrm{~min}$. The Caeté, Ribeirão das Neves, and Pedro Leopoldo counties areas are delimited by thin black contours, and the stars mark the location of hail reports. The small squares along the storms' trajectories indicate the time every $5 \mathrm{~min}$, and the larger squares the time every $40 \mathrm{~min}$ (UTC; numbers at the left of the squares). The satellite-derived clusters were displaced to account for the parallax error.

Additionally, vertical cross sections nearly through the hook echoes (Figs. 7c,f) evidence the bounded weak echo region (BWER; e.g., Marwitz 1972) associated with the absence of large hydrometeors within the intense updraft, which is also characteristic of supercells.

The CTS caused more lightning strikes than the PLS in the first hour after initiation (Fig. 6). Both storms present an increase in lightning activity before hailfall, which matches the leftward turn of the radar-derived trajectories. This rapid increase in lightning activity that is observed before severe weather occurs is referred to as a lightning jump (Goodman et al. 1988). This pattern also suggests the lightning activity increased when the mesocyclones intensified, since the deviant motion became more pronounced. CTS dissipates nearly one hour after the hail occurrence, but the PLS intensifies after causing hail. CTS dissipation occurs in nearly the same period of PLS intensification. It is possible that the gust front from the CTS intensifies the PLS updraft as reported by Goodman and Knupp (1993) and others, or the compensatory subsidence from PLS causes CTS weakening.

\section{c. Temporal evolution of the satellite-derived parameters}

In this section, the 1-min satellite-derived parameters and the lightning density are analyzed. The objective is to evaluate what parameters show better indications of severe weather in the temporal trends and what is the lead time.

Figure 8 shows the temporal trends in the satellitederived parameters. The CTS $10.35-\mu \mathrm{m}$ Tb (Fig. 8a) 
(a) CTS 1730 UTC $-1.4^{\circ} \mathrm{PPI}$

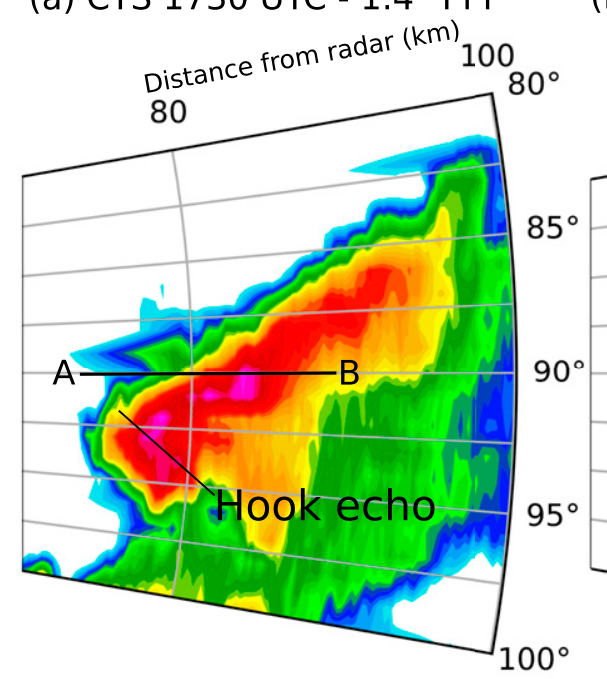

(b) CTS 1730 UTC $-5.0^{\circ} \mathrm{PPI}$

pistance from radar $(\mathrm{km}) 100$

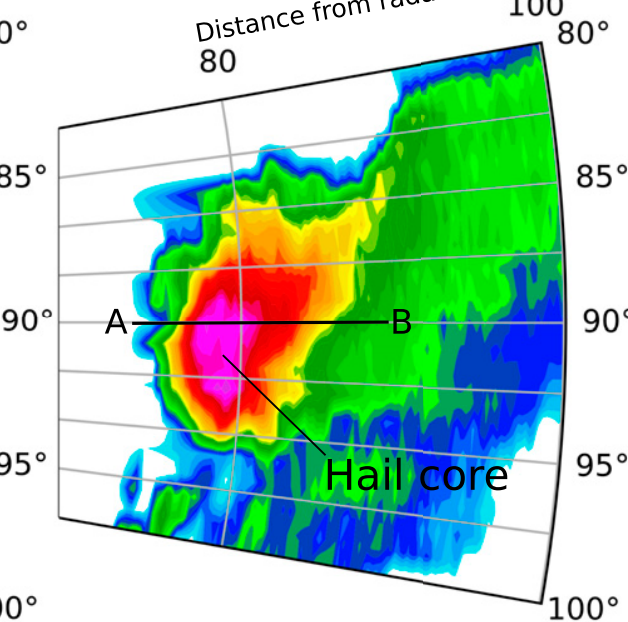

(e) PLS 1930 UTC - 7.0 PPI

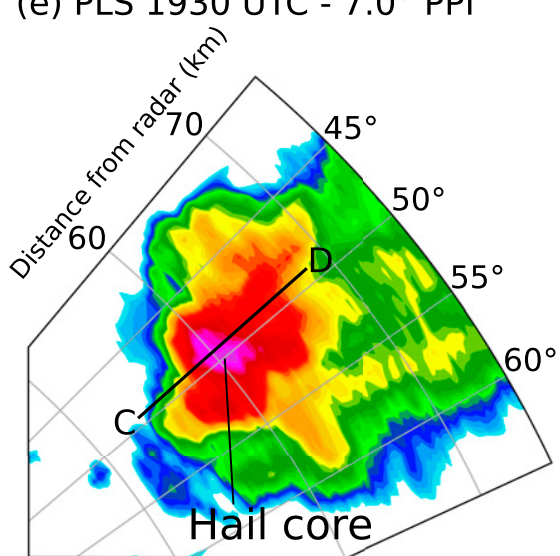

(c) CTS 1730 UTC - $90^{\circ}$ (d) PLS 1930 UTC - 2.3० PPI

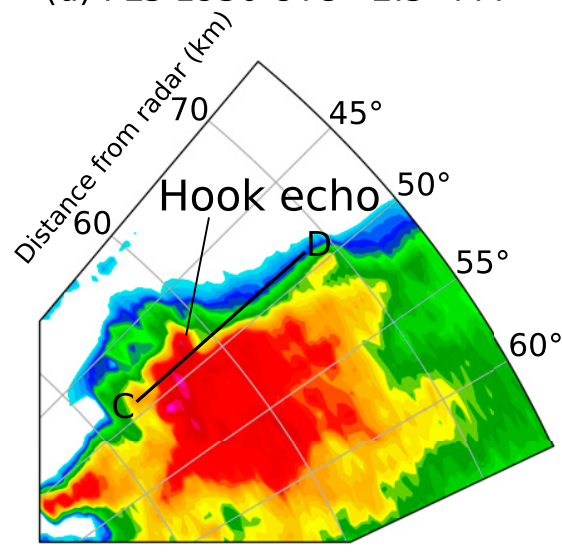

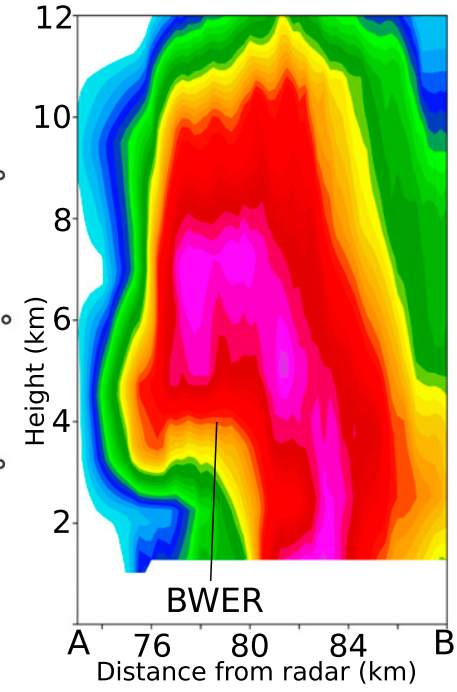

(f) PLS 1930 UTC - 49

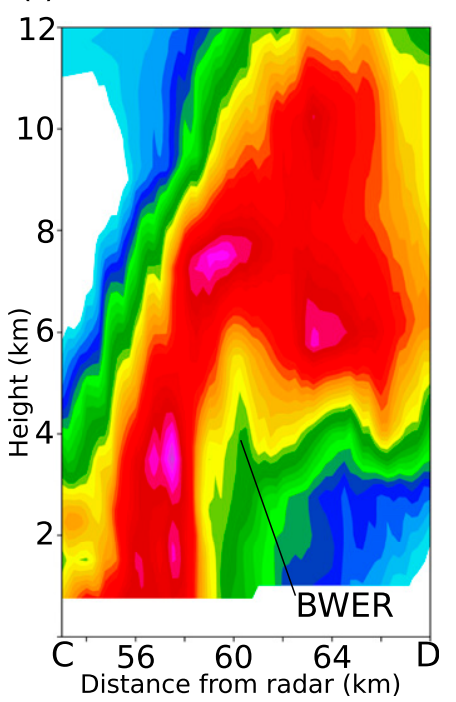

FIG. 7. Mateus Leme C-band radar reflectivity factor (dBZ) plots for CTS and PLS. CTS (a) $1.4^{\circ}$ and (b) $5.0^{\circ}$ PPIs and (c) vertical cross section along the $90^{\circ}$ azimuth between A and B at 1730 UTC 29 Nov 2017. PLS (d) $2.3^{\circ}$ and (e) $7.0^{\circ}$ PPIs and (f) vertical cross section along the $49^{\circ}$ azimuth between C and D at 1930 UTC 29 Nov 2017. Hook echoes, hail cores, and BWERs are indicated.

varies around the value of $225 \mathrm{~K}$ before $1705 \mathrm{UTC}$, when it drops to a minimum of $216 \mathrm{~K}$. This decrease in $\mathrm{Tb}$ is observed in the $\mathrm{Tb}$ temporal trend (Fig. $8 \mathrm{~b}$ ) as a minimum cooling rate of $-3 \mathrm{~K} \mathrm{~min}^{-1}$. This moment is when the first deep updraft of CTS occurs (Fig. 5d). After this abrupt decrease, $\mathrm{Tb}$ remains steady between 215 and $220 \mathrm{~K}$. Another intense updraft occurs after 1728 UTC and causes a Tb decrease of nearly $12 \mathrm{~K}$ in $7 \mathrm{~min}$, which is equivalent to an average cooling of $1.71 \mathrm{~K} \mathrm{~min}^{-1}$ or $25.65 \mathrm{~K}$ in $15 \mathrm{~min}$, more than 3 times greater than the threshold of an 8-K cooling in $15 \mathrm{~min}$ found in Mecikalski and Bedka (2006) for a vigorous updraft.
The decrease in minimum $10.35-\mu \mathrm{m}$ Tb after 1728 UTC (Fig. 8a) and the minimum Tb temporal trend occurred at 1730 UTC (Fig. 8b) precedes the most probable time of hailfall by nearly $10 \mathrm{~min}$. These trends are accompanied by an increase in lightning activity from 19 lightning flashes between 1725 and 1730 UTC to 46 flashes in the next 5 min (lightning jump), which precedes the severe event nearly $10-15 \mathrm{~min}$, in agreement with other studies (e.g., Williams et al. 1999; Gatlin and Goodman 2010; Schultz et al. 2011).

The updraft observed after 1728 UTC is responsible for an increase in the trispectral difference (Fig. 8c), 

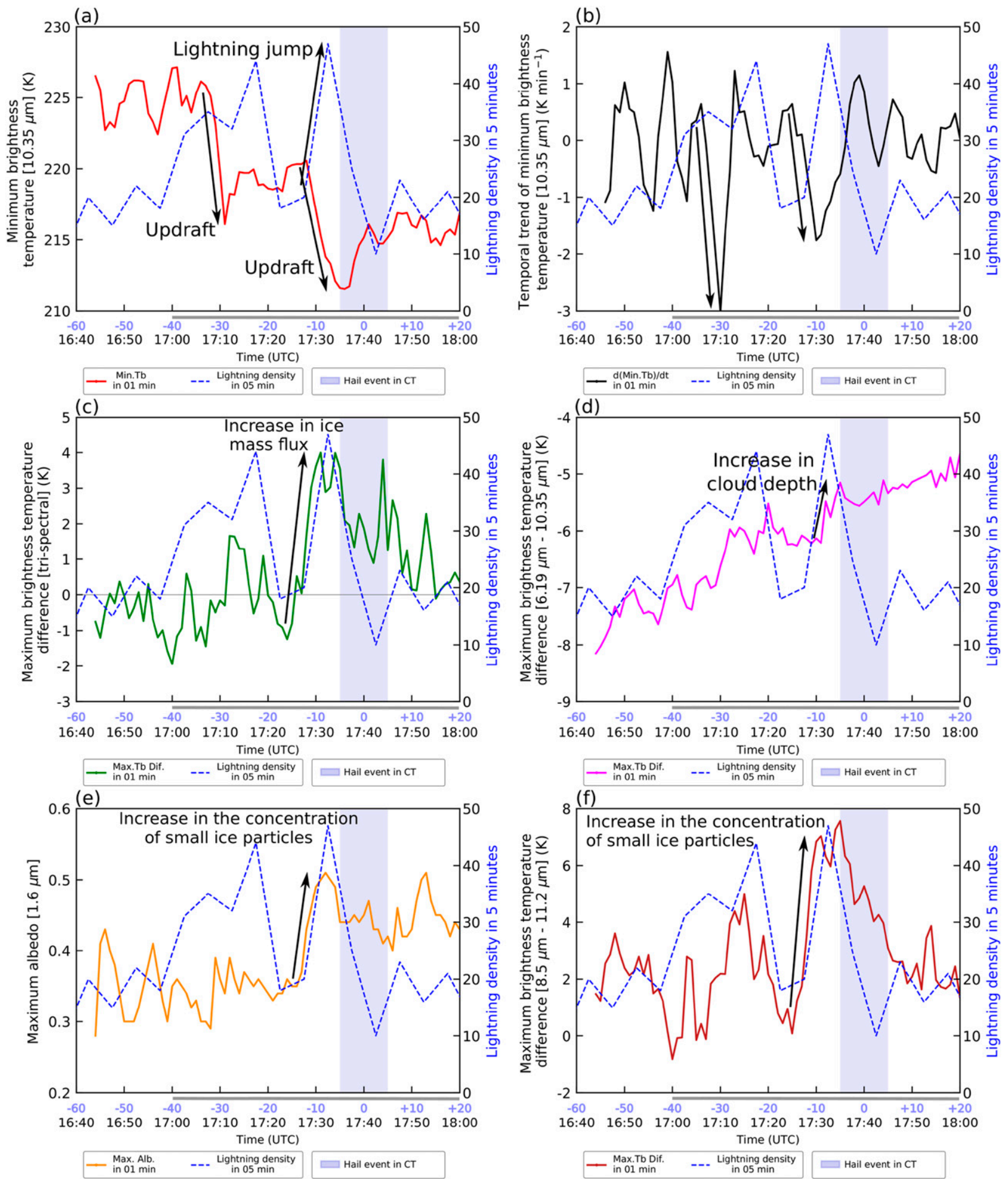

FIG. 8. Temporal variation of (a) minimum $10.35-\mu \mathrm{m} \mathrm{Tb}$ (K; red line), (b) temporal trend of $10.35-\mu \mathrm{m} \mathrm{Tb}\left(\mathrm{K}\right.$ min $^{-1}$; black line), (c) maximum trispectral difference (K; green line), (d) maximum difference between 6.19- and 10.35- $\mu \mathrm{m} \mathrm{Tb}$ (K; magenta line), (e) maximum 1.6- $\mu \mathrm{m}$ albedo (yellow line), and (f) maximum difference between 8.5- and 11.2- $\mu \mathrm{m} \mathrm{Tb}(\mathrm{K}$; dark red line) for the CTS cluster using GOES-16 data every 1 min. The blue dashed line is the lightning strikes density (right vertical axis). The lightning density value is centered in the middle of the 5-min period of accumulation. The shaded area is the estimated time of hailfall in Caeté. On the $x$ axis, the colored labels are minutes relative to hailfall and black labels are time (UTC). The main physical processes associated with the trends are described. The gray line below the $x$ axis indicates the periods when a hook echo was evident on radar in low elevation scans and/or a BWER was evident in cross sections. 
which changes from negative before 1728 UTC to positive after this time, and attains nearly $4^{\circ} \mathrm{C}$ between 1730 and 1735 UTC. This behavior occurs in response to the increase in cloud-top ice crystals as the updraft penetrates the upper troposphere (Ackerman et al. 1990). The increase in the concentration of small ice particles at the cloud top is the explanation for the increase in albedo (Fig. 8e) as well, since small ice particles reflect more solar radiation in the $1.6-\mu \mathrm{m}$ band than large ice particles. The 8.5-11.2- $\mu \mathrm{m}$ Tb difference (Fig. 8f) behaves very similarly to the other variables, with an increase in the difference preceding the hail event and in phase with the lightning activity. This increase is associated with an increasing amount of ice crystals in the top of the convective cloud.

The 6.19-10.35- $\mu \mathrm{m}$ difference (Fig. 8d) also increases with the time, but the temporal trend is more continuous and only shows the cloud-top height is increasing. The stratosphere was at nearly $120 \mathrm{hPa}$ according to the 1200 UTC observed sounding (Fig. 4) and the minimum tropopause temperature was $-77^{\circ} \mathrm{C}(196 \mathrm{~K})$, while the minimum $\mathrm{Tb}$ of CTS was $212 \mathrm{~K}\left(-61^{\circ} \mathrm{C}\right)$, which indicates this storm did not penetrate into the stratosphere. The 6.19-10.35- $\mu \mathrm{m}$ difference does not describe the short-time storm variability associated to the updraft intensification, which agrees with the behavior found by Yost et al. (2018). The area and area expansion (not shown) have a similar behavior, that is, they capture the intensification but show no short-term variability. Apke et al. (2018) also concluded that the trends in upper-level divergence (which can be roughly related to the anvil area expansion) are not useful in describing short-term storm intensification, in particular for supercell storms that present cyclic behavior.

Figure 9 presents the same parameters of Fig. 8, but for the PLS. A clear lightning jump is observed prior to the first severe event $(2-\mathrm{cm}$ hail and wind damage in Ribeirão das Neves) at nearly 1900 UTC. There is a decrease in 10.35- $\mu \mathrm{m} \mathrm{Tb}$ (Fig. 9a) in the same period, as well as an increase in the trispectral (Fig. 9c) and 8.5-11.2- $\mu \mathrm{m}$ differences (Fig. 9f) and an increase in the 1.6- $\mu \mathrm{m}$ albedo (Fig. 9e), all of them indicating an intensification of the convective updraft.

The period before the second severe event caused by PLS (5-cm hail in Pedro Leopoldo) was remarkably different from the periods before the other severe events in terms of lightning activity. A decrease in lightning density occurs after 1900 UTC, and the lightning density remains stable around 20 flashes per 5 min until 1930 UTC. The lightning density then increases rapidly at nearly the same time the severe hail occurred in Pedro Leopoldo, not before it as is commonly observed. The lightning density increases to more than 150 flashes per $5 \mathrm{~min}$ after the severe event, which is one order of magnitude greater than before. This period of high lightning density of PLS will be analyzed later in this section.

The 10.35- $\mu \mathrm{m} \mathrm{Tb}$ decreases between 1916 and 1920 UTC in association with a subtle lightning density increase between 1915 and 1920 UTC. In the same period, the other parameters show a decrease, even though the tendencies are expected be positive in areas of convective invigoration. On the other hand, the values of the satellite parameters are high compared to the CTS (Fig. 8) and the period preceding the first severe weather event of PLS. For example, the trispectral difference (Fig. 9c) varies between $3^{\circ}$ and $8^{\circ} \mathrm{C}$ before and during the second severe weather event of PLS in Pedro Leopoldo, while it peaks at $4^{\circ} \mathrm{C}$ before the CTS event. We hypothesize the PLS enters in the mature stage after the first severe weather event, when the $10.35-\mu \mathrm{m} \mathrm{Tb}$ is lower than $210 \mathrm{~K}$. Both the trispectral difference (Fig. 9c) and the 8.5-11.2- $\mu \mathrm{m}$ difference (Fig. 9f) indicate there is an increase in ice mass flux and in the concentration of small ice particles at the cloud top, which are associated with an active updraft. The 6.19-10.35- $\mu \mathrm{m}$ difference (Fig. 9d) denotes a slow increase in cloud depth with time, but no jump before the severe event as observed for CTS (Fig. 8d).

The evolution of the reflectivity profile and VIL derived from the C-band radar for CTS and PLS is shown in Fig. 10. The updrafts as inferred by the decreases in $10.35-\mu \mathrm{m} \mathrm{Tb}$ are consistent with reflectivity increases above the freezing level and at the top of the storm, mainly for the CTS (Fig. 10a). There is an increase in reflectivity below and near the $0^{\circ} \mathrm{C}$ isotherm and in VIL before hailfall in both cases, but for the PLS (Fig. 10b) there is a noticeable decrease in reflectivity and VIL associated with the hailfalls, which is consistent with the decrease in hydrometeors within the storm as precipitation occurs.

The maturation of PLS after 1910 UTC is supported by the $10.35-\mu \mathrm{m} \mathrm{Tb}$, which becomes lower than $210 \mathrm{~K}$. This value is nearly the temperature of the equilibrium level as indicated by the 1200 UTC observed sounding (Fig. 4), which indicates the PLS updraft probably reached the tropopause (Bedka and Khlopenkov 2016). When the updraft reaches the tropopause and encounters the stable air in this layer, the primary growth occurs in the horizontal, and it can be seen as an anvil area expansion (Mecikalski et al. 2016). Figure 11 evidences that the area increases to almost $2000 \mathrm{~km}^{2} 20-30$ min before the first PLS severe weather event, decreases after 1852 UTC, and then increases more rapidly after 1900 UTC. This last rapid increase in the PLS cluster area denotes the horizontal expansion of the anvil as the updraft reaches the tropopause (Machado and Laurent 2004; Mecikalski et al. 2016; 

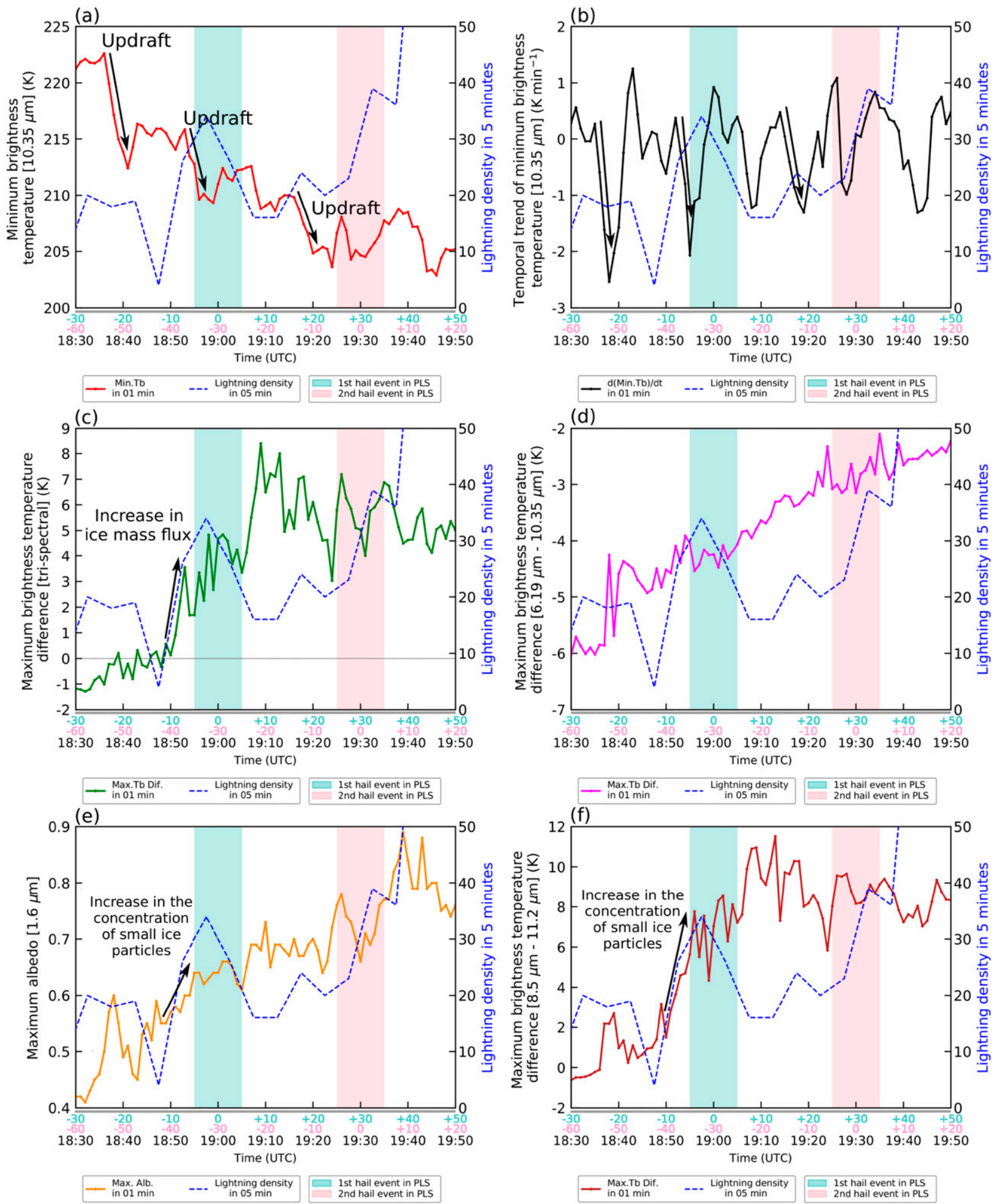

FIG. 9. As in Fig. 8, but for the PLS cluster. The leftmost shaded area is the Ribeirão das Neves 2-cm hail and wind event, and the rightmost shaded area is the Pedro Leopoldo 5-cm hail event. On the $x$ axis, the colored labels are minutes relative to hailfall (for each event according to the color) and black labels are time (UTC). The main physical processes associated with the trends are described. The gray line below the $x$ axis indicates the periods when a hook echo was evident on radar in low elevation scans and/or a BWER was evident in cross sections. 

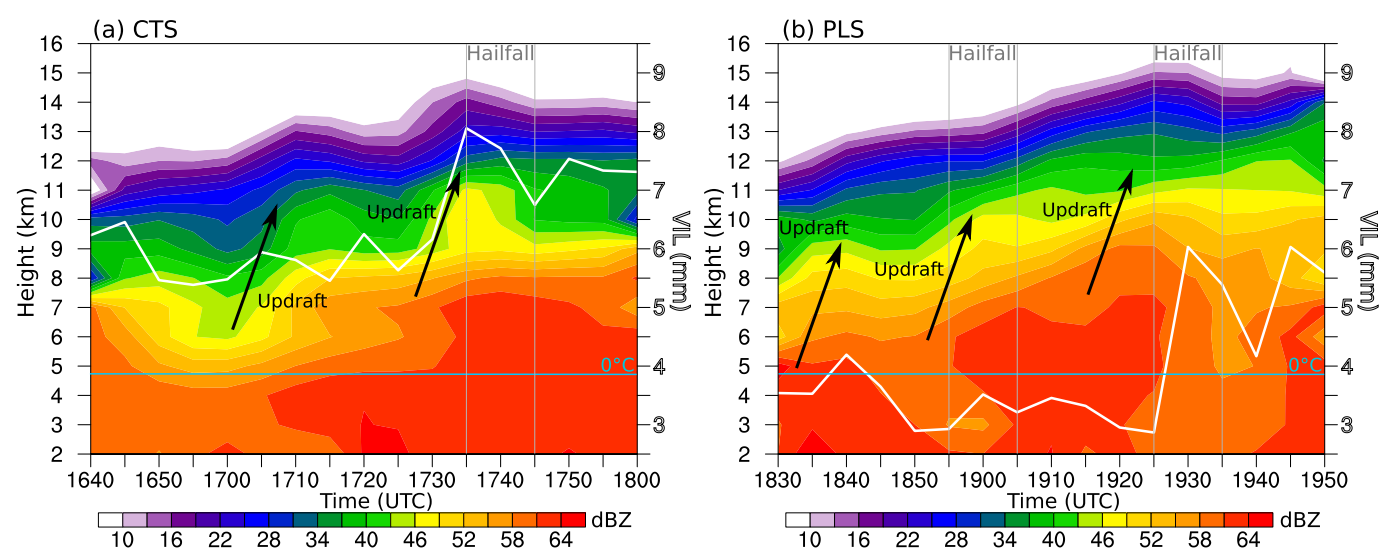

FIG. 10. Temporal evolution of the vertical profile of reflectivity ( $\mathrm{dBZ}$; shaded) and average VIL (mm; white line) for the (a) CTS and (b) PLS clusters. The estimated times of hailfall are shown between gray lines. The light blue line indicates the $0^{\circ} \mathrm{C}$ isotherm height estimated using the 1200 UTC sounding (Fig. 4). The updrafts as inferred by the 10.35- $\mu \mathrm{m} \mathrm{Tb}$ decreases (Fig. 8a for CTS and Fig. 9a for PLS) are indicated by black arrows.

Apke et al. 2018). At 1932 UTC, the PLS cluster merges with another cluster and the area expansion is not monitored anymore. No severe weather reports were found in this period, but the lightning trends suggest that the PLS intensified even further after the $5-\mathrm{cm}$ hailfall in Pedro Leopoldo at nearly 1930 UTC.

The satellite-derived parameters and lightning density during the mature stage of PLS are shown in Fig. 12. The lightning density increase is evident after 1930 UTC, when the lightning density increases from nearly 30 to more than 150 lightning flashes per $5 \mathrm{~min}$ in a period of roughly $30 \mathrm{~min}$. The radar reflectivity signature (not shown) depicts a prominent hook echo at this time, which is a signature of updraft rotation and presence of a mesocyclone in the thunderstorm. It is possible that the mesocyclone played a role on the maintenance of the PLS by inducing greater thunderstorm organization and limiting the disruption of the updraft by the downdraft (e.g., Houze 2004).

The 10.35- $\mu \mathrm{m} \mathrm{Tb}$ (Fig. 12a) varies between 202 and $209 \mathrm{~K}$ in the period, which is slightly lower than the estimated temperature of the equilibrium layer $(210 \mathrm{~K})$. Some updrafts are more intense and cause momentary 10.35- $\mu \mathrm{m} \mathrm{Tb}$ decrease, such as between 1940 and 1945 UTC and between 2012 and 2017 UTC, but there is no total trend in $10.35-\mu \mathrm{m} \mathrm{Tb}$ in the period. The trispectral difference (Fig. 12c) and 8.5-11.2- $\mu \mathrm{m} \mathrm{Tb}$ difference (Fig. 12b) indicate increasing ice mass flux. The difference between 6.9- and 10.35- $\mu \mathrm{m} \mathrm{Tb}$ (Fig. 12d) is steady at nearly $-2^{\circ} \mathrm{C}$, which indicates the thunderstorm depth remains constant during the period and reinforces the idea that the updrafts are not able to reach the stratosphere (overshoot) at this moment. As the storm expands and attains the mature stage, the variability of the parameters decreases, and the 1-min scans do not produce additional information of the storm for nowcasting purposes.

Even though both storms produced large hail, there were significant differences between the two severe storms. The satellite-derived parameters and lightning activity suggest the CTS storm intensified, produced large hail, and dissipated, while PLS lightning activity increased further after the large hail and maturation. The CTS was shallower and did not present characteristic overshooting top or V shape, while the PLS was deeper and had severe signatures in satellite imagery. Despite these differences, the 1-min trends proved to

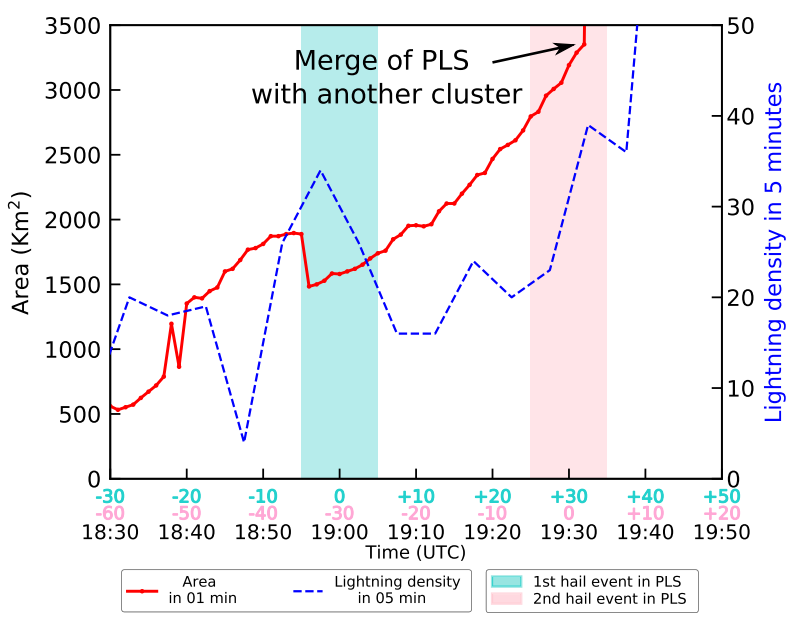

FIG. 11. Temporal variation of the PLS cluster area $\left(\mathrm{km}^{2}\right)$. The leftmost shaded area is the Ribeirão das Neves 2-cm hail and wind event, and the rightmost shaded area is the Pedro Leopoldo $5-\mathrm{cm}$ hail event. On the $x$ axis, the colored labels are minutes relative to hailfall (for each event according to the color) and black labels are time (UTC). 

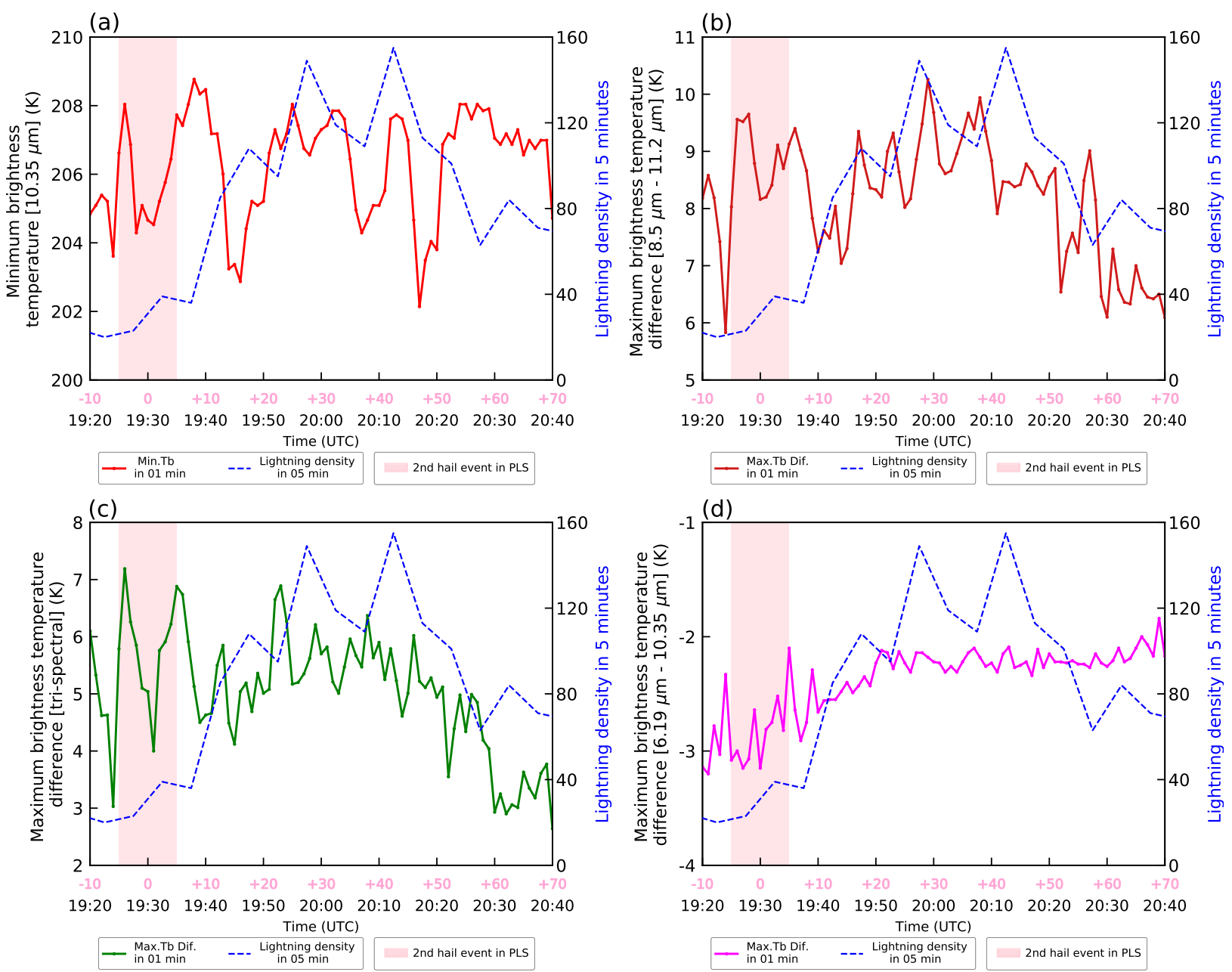

FIG. 12. Temporal variation of (a) minimum 10.35- $\mu \mathrm{m} \mathrm{Tb}$ (K; red line), (b) maximum difference between 8.5 - and 11.2- $\mu \mathrm{m} \mathrm{Tb}$ (K; dark red line), (c) maximum trispectral difference (K; green line), and (d) maximum difference between 6.19 and $10.35-\mu \mathrm{m} \mathrm{Tb}(\mathrm{K}$; magenta line) for the PLS cluster mature stage using GOES-16 data every $1 \mathrm{~min}$. The blue dashed line is the lightning strikes density (right vertical axis). The lightning density value is centered in the middle of the 5-min period of accumulation. The shaded area is the estimated time of hailfall in Pedro Leopoldo.

be useful indicators of the severe hailfalls. This study is the first to contrast two storms that occurred in the same environment and produced similar severe weather impacts but had different satellite signatures. It is also the first to highlight the forecasting potential of the 1-min satellite-derived parameters trends even for such different storms.

\section{d. Comparison of satellite parameters in different temporal resolutions}

Figure 13 shows the satellite-derived parameters with different temporal resolutions for the CTS cluster. The 1-min trends show much more variability and details than the other temporal resolutions. The $10.35-\mu \mathrm{m}$ Tb decrease from 1728 to 1736 UTC (Fig. 13a), which precedes the hail event, is not captured by the 10- and 15-min resolutions. The minimum $10.35-\mu \mathrm{m} \mathrm{Tb}$ of the entire CTS lifetime ( $212 \mathrm{~K}$ at 1736 UTC) is missed in the 10- and 15-min resolutions as well. The 5-minresolution data, however, are able to represent both the $\mathrm{Tb}$ drop and the $\mathrm{Tb}$ minimum with good similarity to the 1-min data. The lead time of the $10.35-\mu \mathrm{m} \mathrm{Tb}$ (i.e., decrease in $\mathrm{Tb}$ preceding the hail occurrence) is similar when using data with 1 and $5 \mathrm{~min}$, but is much lower using data with $10-$ or 15 -min resolutions. The decrease in $\mathrm{Tb}$ and the association of it with the intensification of the CTS updraft would be noted only at the time of the event for the 10- and 15-min resolutions, and the updraft intensity estimated by $\mathrm{Tb}$ trends is lower (Mecikalski et al. 2016).

The other satellite-derived parameters preceding the CTS hail event (Figs. 13b-d) show a similar pattern. 

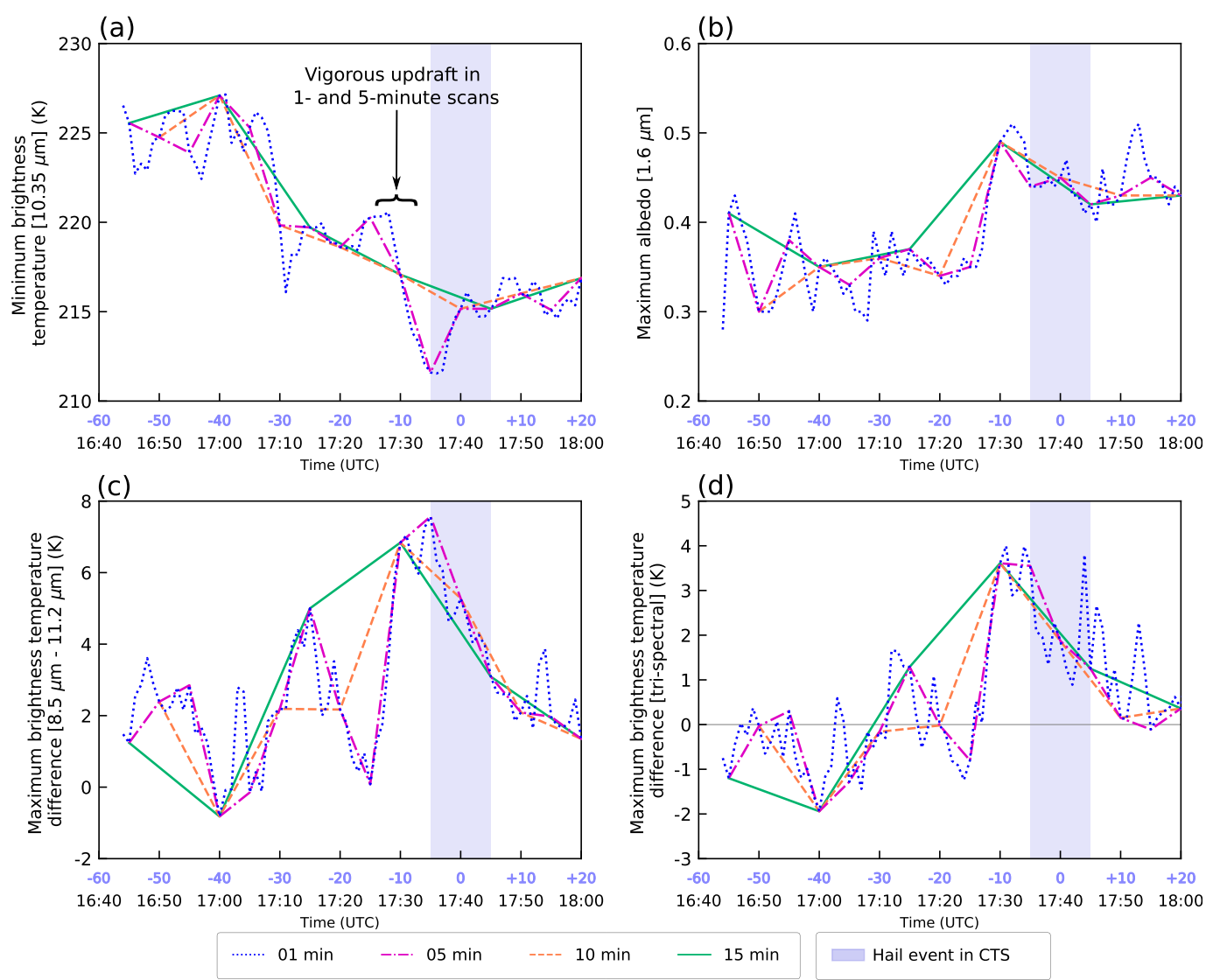

FIG. 13. Temporal variations of the satellite-derived parameters each 1 (blue dotted line), 5 (magenta dot-dashed line), 10 (orange dashed line), and 15 (green continuous line) min for the CTS cluster. (a) Minimum 10.35- $\mu \mathrm{m} \mathrm{Tb}$ (K), (b) maximum 1.6- $\mu \mathrm{m}$ albedo, (c) maximum difference between 8.5 - and 11.2- $\mu \mathrm{m} \mathrm{Tb}(\mathrm{K})$, and (d) maximum trispectral difference $(\mathrm{K})$. The shaded area is the estimated time of hailfall in Caeté. On the $x$ axis, the colored labels are minutes relative to hailfall and black labels are time (UTC). The occurrences of vigorous updrafts [8 K $(15 \mathrm{~min})^{-1}$ decrease in $\left.10.35-\mu \mathrm{m} \mathrm{Tb}\right]$ noticed in 1- and 5-min scans but not in 10- and 15-min scans are indicated.

The 5-min curves follow the 1-min curves closely, even though they are not able to capture the 1-min pulses. For the 1.6- $\mu \mathrm{m}$ albedo (Fig. 13b) the maximum that precedes the CTS event occurs at 1732 UTC (close to 1730 UTC, when 5-, 10-, and 15-min resolutions have a measurement), and the trends are also observed in the 5-, 10-, and 15-min data. However, the increase in albedo would be noticed at these resolutions only at the time of maximum 1.6- $\mu \mathrm{m}$ albedo (1730 UTC), while the increase in albedo with 1-min data would be noticed $3 \mathrm{~min}$ before. The $8.5-11.2-\mu \mathrm{m}$ differences and the trispectral difference present two maxima at nearly 1713 and 1734 UTC and a minimum between them at 1725 UTC. These variations are again better described by the 1- and 5-min data, which allows for better monitoring of the increases and decreases in storm intensity. The 15-min curve for the 8.5-11.2- $\mu \mathrm{m}$ difference (Fig. 13c), for example, is not able to depict the minimum at nearly 1725 UTC, and consequently the positive tendency after this time. The $6.19-10.35-\mu \mathrm{m}$ difference, area, and area expansion were not shown because the 1-min image and 15-min images are similar, and, at least for these events, these parameters do not introduce new information at higher temporal resolutions.

The same graphics are shown for the PLS in Fig. 14. The tendencies lead to similar conclusions in comparison to the CTS case: the 5-min data are able to follow the 1-min data in most of the peaks. Even though the 10- and 15-min data present a $10.35-\mu \mathrm{m} \mathrm{Tb}$ decrease with time (Fig. 14a), there is no discernible rapid decrease that could be associated with an updraft intensification before the first severe event from PLS, precluding the issuance of a warning. After 1910 UTC, when the PLS enters the mature stage, the trends are less useful for predicting the severe weather occurrences, and the advantages of the 1- and 5-min data are less evident. However, other signatures such as area expansion and 

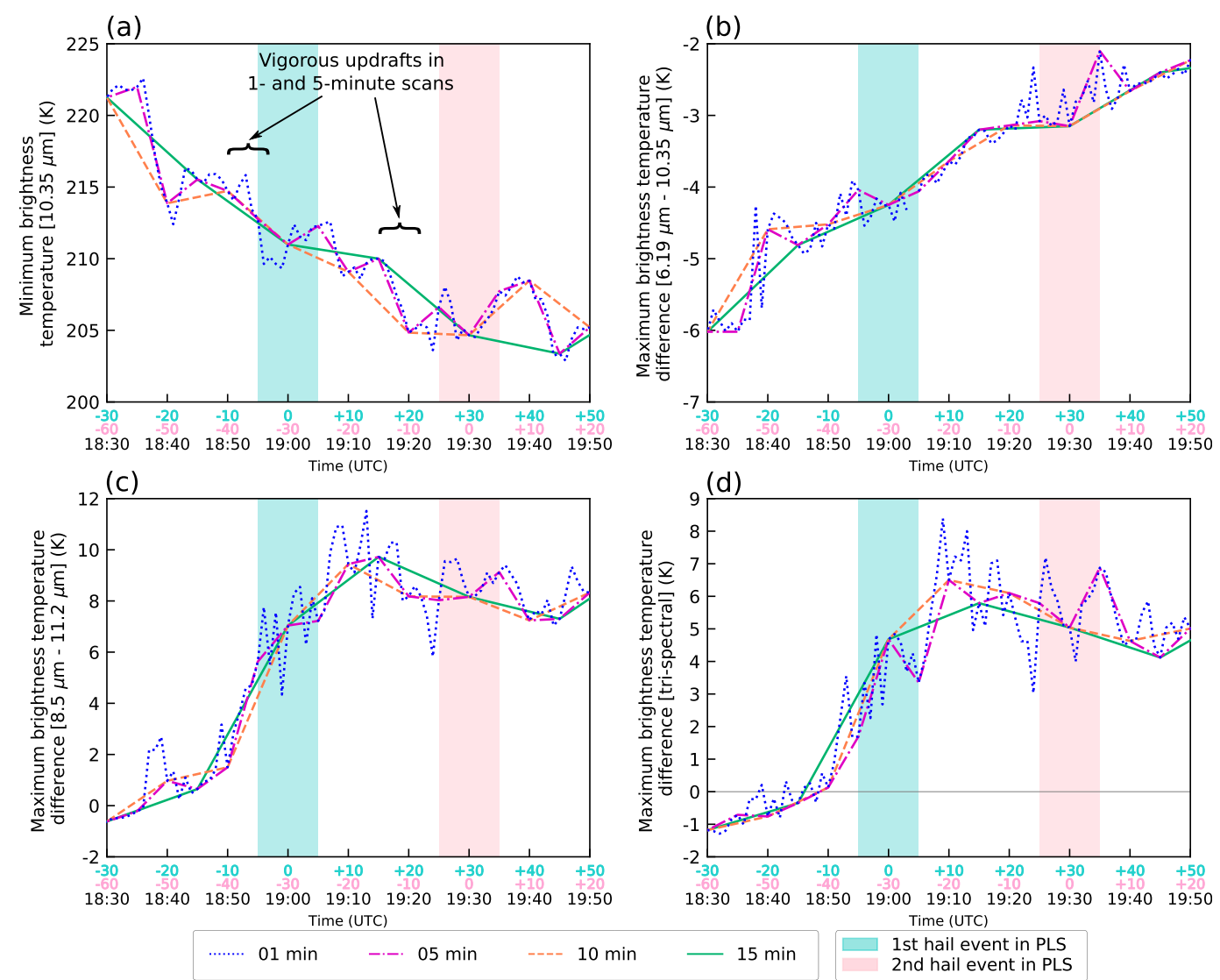

FIG. 14. Temporal variations of the satellite-derived parameters each 1 (blue dotted line), 5 (magenta dot-dashed line), 10 (orange dashed line), and 15 (green continuous line) min for the PLS cluster. (a) Minimum 10.35- $\mu \mathrm{m} \mathrm{Tb}$ (K), (b) maximum difference between 6.9- and 10.35- $\mu \mathrm{m} \mathrm{Tb}(\mathrm{K})$, (c) maximum difference between 8.5 and 11.2- $\mu \mathrm{m}$ $\mathrm{Tb}(\mathrm{K})$, and (d) maximum trispectral difference (K). The leftmost shaded area is the Ribeirão das Neves 2-cm hail and wind event, and the rightmost shaded area is the Pedro Leopoldo 5-cm hail event. On the $x$ axis, the colored labels are minutes relative to hailfall (for each event according to the color) and black labels are time (UTC). The occurrences of vigorous updrafts $\left[8 \mathrm{~K}(15 \mathrm{~min})^{-1}\right.$ decrease in $\left.10.35-\mu \mathrm{m} \mathrm{Tb}\right]$ noticed in 1 - and 5 -min scans but not in 10- and 15-min scans are indicated.

the presence of $\mathrm{U}$ or $\mathrm{V}$ shape, can be used by a forecaster to evaluate the storm's severity.

The MDS 1-min data, as compared to the more conventional scanning resolutions of 5,10 , and $15 \mathrm{~min}$, show details that the other resolutions are not able to capture. Variations in cloud-top properties and updraft intensity occurring in a few minutes are only measured by the rapid scan. The lead times of 1-min trends were nearly 12 min for the CTS event and 8 and 12 min for the first and second PLS events, respectively, which is lower than the lead times found by Bedka et al. (2015) for storms in the United States. For nowcasting purposes, the 5-min scans can describe the main tendencies of the satellite-derived parameters and also filter the 1-min trends that may not be associated directly with a trend in storm intensity. A warning system based on the 1-min data without any temporal filter could cause too many false alarms. An example appears in the trends of the trispectral difference for the PLS (Fig. 14d) between 1905 and 1940 UTC, in which the 1-min data show several maxima and minima within an oscillatory pattern while the 5-min data present a smoothed curve indicating a more stable behavior of the parameter. The 1-min trends in this case could lead to false alarms. A possible explanation for the results using 5-min data is the fact that most updrafts accompanied by $\mathrm{Tb}$ decrease occur in the range between 5 and $10 \mathrm{~min}$, which allows at least one measurement of the $\mathrm{Tb}$ drop with 5-min interval. Bedka and Khlopenkov (2016) developed an algorithm for overshooting top detection that incorporates parameters such as visible channel texture, which improves the association of 1-min trends with severe weather reports by reducing false alarms. Also, the indication of severe weather by the 10- and 15-min trends is better before the first PLS event (Fig. 14) than before the CTS event (Fig. 13), 
which suggests there is a case-to-case variability in the skill of each scan frequency. This analysis relies on only two cases and a statistical analysis with a high number of cases is deserved.

\section{Conclusions}

Two storms responsible for severe hail and wind reports in southeastern Brazil were analyzed using the GOES-16 MDS scans. Lagrangian satellite-derived quantities commonly used in nowcasting were calculated for these storms by using a cluster tracking algorithm. The analysis benefited from data of a C-band radar and a lightning detection network in the same region.

The storm responsible for $5-\mathrm{cm}$ hail in Caeté presented severe signatures in radar but not in the satellite imagery. The minimum cloud-top $10.35-\mu \mathrm{m} \mathrm{Tb}$ was $212 \mathrm{~K}$, which is higher than the minimum of other storms nearby. The satellite-derived parameters indicate the CTS probably did not reach the equilibrium level at the tropopause, which relates to its relatively warm cloud top. Between 10 and $15 \mathrm{~min}$ before the occurrence of hail caused by the CTS, the satellite-derived parameters showed a rapid decrease in $10.35-\mu \mathrm{m} \mathrm{Tb}$ (peaking at $-3 \mathrm{~K} \mathrm{~min}^{-1}$ ), which is much more intense than the decrease rates found by Mecikalski and Bedka (2006) using satellite data with $15 \mathrm{~min}$ of temporal resolution, and a lightning jump. The other parameters also indicated increasing concentration of small ice particles at the cloud top and increasing ice mass flux. The $6.19-10.35-\mu \mathrm{m}$ difference shows an increase in value, but does not show any signature of penetrative cloud and does not show the short-time variability, but a nearly continuous monotonic increase in the cloud depth. The 6.19-10.35- $\mu \mathrm{m}$ difference did not attain positive values, which corroborates that an overshooting top was not observed in the CTS. The CTS weakens after the severe weather event and dissipates at nearly 1900 UTC.

The PLS also presented supercell characteristics and produced two severe weather events at different times. For the first severe weather event, the parameters indicated a rapid decrease in cloud-top temperature, increase in ice mass flux, and increase in storm depth 10-15 min before the event, plus a lightning jump. The second event occurred during the transition of PLS to the mature stage, when the satellite-derived parameters stabilize and subsequently the lightning density increases. There are no clear tendencies in the satellite-derived parameters that could indicate updraft invigoration, but only the maintenance of an intense updraft. However, radar signatures and the occurrence of a V shape during some moments after maturation (not shown) and high lightning activity suggest the storm was still severe at this time. It is also possible that severe weather occurred between the first and the second PLS events, but no reports were found.

The PLS evolved to the mature stage after 1940 UTC, with lightning densities over 150 lightning flashes per $5 \mathrm{~min}$ in some moments and a relative stability of the satellite-derived parameters, along with $10.35-\mu \mathrm{m}$ near and below the equilibrium-level temperature. It is possible that the deeper updraft and greater increase in ice mass flux of the PLS are associated with a sustained mesocyclone that maintained the storm organization for more time than the CTS. The area where the PLS formed and the time of the day (late afternoon) suggest the CAPE was higher than when the CTS formed, which could have contributed to a deeper storm. In general, the satellite and radar observations indicate the studied storms had similar characteristics of severe storms in other parts of the world (e.g., Bedka et al. 2015; Mecikalski et al. 2016; Yost et al. 2018).

The advantages of the rapid scan in nowcasting are clear when comparing the 1-min data with the operational 15-min data. There are several rapid oscillations in the storm intensity, such as updraft intensity, cloudtop glaciation/increase in ice mass flux, and storm depth changes, that are only perceivable using the 1-min data. This is in agreement with Mecikalski et al. (2016), which showed the 1-min 10.35- $\mu \mathrm{m} \mathrm{Tb}$ has good correlation with the amount of CAPE in the layer where the updraft is occurring. One of the main findings of this study is that the 5-min data showed good representation of the storm-scale oscillations in this case. Also, the 5-min data are able to smooth the oscillations shown in the 1-min data and can facilitate the nowcasting process by reducing the false alarm to severe weather. A meteorologist monitoring the 1-min parameters trend would see several positive and negative trends that are not associated with severe weather. The benefit of 1-min scans is very high relative to 10 - or 15 -min scans, but is not significant against 5-min scans in the present methodology. However, the use of additional information, such as visible channel texture, can reduce the 1-min false alarms in automated algorithms (Bedka and Khlopenkov 2016). Another advantage of the 1-min trends is the indication of increasing severe weather potential even for storms that do not have a distinct severe signature (e.g., overshooting top, $\mathrm{V}$ shape), which allows the forecaster to issue a warning when these signatures are absent.

The 1-min trends in the satellite-derived parameters proved to be an important tool for nowcasting and are 
much better at describing storm intensity fluctuations than the operational 15- and 10-min scans mainly for the convective initiation and maturation periods. The study suggests the investigation of other cases to understand this change of time variability as the storm evolves during the life cycle. The ability of 5-min scans to describe the most important trends in storm intensity can be used to plan operational procedures in satellite scans in the future. Scans of the GOES full disk at 5-min intervals, for example, can help improve nowcasting over a large area, while the rapid scans only focus on a small domain. Also, upcoming research using the MDS rapid scans over South America during the Remote Sensing of Electrification, Lightning, and Mesoscale/Microscale Processes with Adaptive Ground Observations (RELAMPAGO) field campaign may provide additional conclusions regarding the use of rapid scans in nowcasting.

Acknowledgments. The authors acknowledge NOAA NESDIS for providing the MDS scan over the SOS CHUVA area, the CEMIG for providing the Mateus Leme radar data, the Civil Defense of Minas Gerais for damage information, ELAT/INPE for the lightning data, and three anonymous reviewers for their suggestions. The scientific results and conclusions, as well as any views or opinions expressed herein, are those of the authors and do not necessarily reflect those of NOAA or the Department of Commerce. This study was supported by FAPESP (Grant 2015/14497-0) and NASA (Grant 80NSSC18K1689).

\section{REFERENCES}

Ackerman, S. A., 1996: Global satellite observations of negative brightness temperature differences between 11 and 6.7 um. J. Atmos. Sci., 53, 2803-2812, https://doi.org/10.1175/ 1520-0469(1996)053<2803:GSOONB > 2.0.CO;2.

— - W. L. Smith, H. E. Revercomb, and J. D. Spinhirne, 1990: The 27-28 October 1986 FIRE IFO cirrus case study: Spectral properties of cirrus clouds in the $8-12 \mu \mathrm{m}$ window. Mon. Wea. Rev., 118, 2377-2388, https://doi.org/10.1175/ 1520-0493(1990)118<2377:TOFICC > 2.0.CO;2.

Adler, R. F., and D. D. Fenn, 1979: Thunderstorm vertical velocities estimated from satellite data. J. Atmos. Sci., 36, 1747-1754, https://doi.org/10.1175/1520-0469(1979)036<1747: TVVEFS $>2.0$. CO;2.

— , and R. A. Mack, 1986: Thunderstorm cloud top dynamics as inferred from satellite observations and a cloud top parcel model. J. Atmos. Sci., 43, 1945-1960, https://doi.org/10.1175/ 1520-0469(1986)043<1945:TCTDAI>2.0.CO;2.

Apke, J. M., J. R. Mecikalski, and C. P. Jewett, 2016: Analysis of mesoscale atmospheric flows above mature deep convection using super rapid scan geostationary satellite data. J. Appl. Meteor. Climatol., 55, 1859-1887, https://doi.org/10.1175/ JAMC-D-15-0253.1.
, K. Bedka, E. W. McCaul Jr., C. R. Homeyer, and C. P. Jewett, 2018: Relationships between deep convection updraft characteristics and satellite-based super rapid scan mesoscale atmospheric motion vector-derived flow. Mon. Wea. Rev., 146, 3461-3480, https://doi.org/10.1175/MWR-D-18-0119.1.

Baum, B. A., P. F. Soulen, K. I. Strabala, M. D. King, S. A. Ackerman, W. P. Menzel, and P. Yang, 2000: Remote sensing of cloud properties using MODIS airborne simulator imagery during SUCCESS: 2. Cloud thermodynamic phase. J. Geophys. Res., 105, 11 781-11 792, https://doi.org/10.1029/1999JD901090.

Bedka, K. M., and K. Khlopenkov, 2016: A probabilistic multispectral pattern recognition method for detection of overshooting cloud tops using passive satellite imager observations. J. Appl. Meteor. Climatol., 55, 1983-2005, https://doi.org/ 10.1175/JAMC-D-15-0249.1.

- R. Dworak, J. Brunner, and W. Feltz, 2012: Validation of satellite-based objective overshooting cloud-top detection methods using CloudSat cloud profiling radar observations. J. Appl. Meteor. Climatol., 51, 1811-1822, https://doi.org/ 10.1175/JAMC-D-11-0131.1.

, C. Wang, R. Rogers, L. D. Carey, W. Feltz, and J. Kanak, 2015: Examining deep convective cloud evolution using total lightning, WSR-88D, and GOES-14 super rapid scan datasets. Wea. Forecasting, 30, 571-590, https://doi.org/10.1175/ WAF-D-14-00062.1.

Bedka, K., E. M. Murillo, C. R. Homeyer, B. Scarino, and H. Mersiovsky, 2018: The above-anvil cirrus plume: An important severe weather indicator in visible and infrared satellite imagery. Wea. Forecasting, 33, 1159-1181, https:// doi.org/10.1175/WAF-D-18-0040.1.

Cintineo, J. L., M. J. Pavolonis, J. M. Sieglaff, and A. K. Heidinger, 2013: Evolution of severe and nonsevere convection inferred from GOES-derived cloud properties. J. Appl. Meteor. Climatol., 52, 2009-2023, https://doi.org/10.1175/JAMC-D-12-0330.1.

de Lima Nascimento, E. L., G. Held, and A. M. Gomes, 2014: A multiple-vortex tornado in southeastern Brazil. Mon. Wea. Rev., 142, 3017-3037, https://doi.org/10.1175/MWR-D-13-00319.1.

Durkee, J. D., and T. L. Mote, 2010: A climatology of warmseason mesoscale convective complexes in subtropical South America. Int. J. Climatol., 30, 418-431, https:// doi.org/10.1002/JOC.1893.

Dworak, R., K. Bedka, J. Brunner, and W. Feltz, 2012: Comparison between GOES-12 overshooting-top detections, WSR-88D radar reflectivity, and severe storm reports. Wea. Forecasting, 27, 684-699, https://doi.org/10.1175/WAF-D-11-00070.1.

Fritz, S., and I. Laszlo, 1993: Detection of water vapor in the stratosphere over very high clouds in the tropics. J. Geophys. Res., 98, 22 959-22 967, https://doi.org/10.1029/93JD01617.

Gatlin, P. N., and S. J. Goodman, 2010: A total lightning trending algorithm to identify severe thunderstorms. J. Atmos. Oceanic Technol., 27, 3-22, https://doi.org/10.1175/ 2009JTECHA1286.1.

Goodman, S. J., and K. R. Knupp, 1993: Tornadogenesis via squall line and supercell interaction: The November 15, 1989 Huntsville, Alabama tornado. The Tornado: Its Structure, Dynamics, Prediction, and Hazards, Geophys. Monogr., Vol. 79, Amer. Geophys. Union, 183-199.

—, D. E. Buechler, P. D. Wright, and W. D. Rust, 1988: Lightning and precipitation history of a microburst-producing storm. Geophys. Res. Lett., 15, 1185-1188, https://doi.org/ 10.1029/GL015i011p01185.

Houze, R. A., 2004: Mesoscale convective systems. Rev. Geophys., 42, RG4003, https://doi.org/10.1029/2004RG000150. 
Johnson, A. W., and K. E. Sugden, 2014: Evaluation of soundingderived thermodynamic and wind-related parameters associated with large hail events. Electron. J. Severe Storms Meteor., 9 (5), https://ejssm.org/ojs/index.php/ejssm/article/viewArticle/137.

Lindsey, D. T., D. W. Hillger, L. Grasso, J. A. Knaff, and J. F. Dostalek, 2006: GOES climatology and analysis of thunderstorms with enhanced 3.9- $\mu \mathrm{m}$ reflectivity. Mon. Wea. Rev., 134, 2342-2353, https://doi.org/10.1175/MWR3211.1.

Line, W. E., T. J. Schmit, D. T. Lindsey, and S. J. Goodman, 2016: Use of geostationary super rapid scan satellite imagery by the Storm Prediction Center. Wea. Forecasting, 31, 483-494, https://doi.org/10.1175/WAF-D-15-0135.1.

Machado, L. A. T., and H. Laurent, 2004: The convective system area expansion over Amazonia and its relationships with convective system life duration and high-level wind divergence. Mon. Wea. Rev., 132, 714-725, https://doi.org/10.1175/ 1520-0493(2004)132<0714:TCSAEO > 2.0.CO;2.

_ W. B. Rossow, R. L. Guedes, and A. W. Walker, 1998: Life cycle variations of mesoscale convective systems over the Americas. Mon. Wea. Rev., 126, 1630-1654, https://doi.org/ 10.1175/1520-0493(1998)126<1630:LCVOMC > 2.0.CO;2.

_- W. F. Lima, O. Pinto Jr., and C. A. Morales, 2009: Relationship between cloud-to-ground discharge and penetrative clouds: A multi-channel satellite application. Atmos. Res., 93, 304-309, https://doi.org/10.1016/j.atmosres.2008.10.003.

—_, and Coauthors, 2014: The CHUVA project: How does convection vary across Brazil? Bull. Amer. Meteor. Soc., 95, 13651380, https://doi.org/10.1175/BAMS-D-13-00084.1.

Marwitz, J. D., 1972: The structure and motion of severe hailstorms. Part III: Severely sheared storms. J. Appl. Meteor., 11, 189-201, https://doi.org/10.1175/1520-0450(1972)011<0189:TSAMOS> 2.0.CO;2.

Mecikalski, J. R., and K. M. Bedka, 2006: Forecasting convective initiation by monitoring the evolution of moving cumulus in daytime GOES imagery. Mon. Wea. Rev., 134, 49-78, https:// doi.org/10.1175/MWR3062.1.

, W. M. MacKenzie Jr., M. Koenig, and S. Muller, 2010a: Cloud-top properties of growing cumulus prior to convective initiation as measured by Meteosat Second Generation. Part I: Infrared fields. J. Appl. Meteor. Climatol., 49, 521-534, https:// doi.org/10.1175/2009JAMC2344.1.

,$- \ldots$, M. König, and S. Muller, 2010b: Cloud-top properties of growing cumulus prior to convective initiation as measured by Meteosat Second Generation. Part II: Use of visible reflectance. J. Appl. Meteor. Climatol., 49, 2544-2558, https:// doi.org/10.1175/2010JAMC2480.1.

— C. C. Jewett, J. M. Apke, and L. D. Carey, 2016: Analysis of cumulus cloud updrafts as observed with 1-min resolution Super Rapid Scan GOES imagery. Mon. Wea. Rev., 144, 811830, https://doi.org/10.1175/MWR-D-14-00399.1.

Naccarato, K. P., and O. Pinto Jr., 2009: Improvements in the detection efficiency model for the Brazilian lightning detection network (BrasilDAT). Atmos. Res., 91, 546-563, https:// doi.org/10.1016/j.atmosres.2008.06.019.

Roberts, R. D., and S. Rutledge, 2003: Nowcasting storm initiation and growth using GOES-8 and WSR-88D data. Wea. Forecasting, 18, 562-584, https://doi.org/10.1175/1520-0434(2003)018<0562: NSIAGU $>2.0 . \mathrm{CO} ; 2$.

Rotunno, R., and J. B. Klemp, 1982: The influence of the shear-induced pressure gradient on thunderstorm motion. Mon. Wea. Rev., 110, 136-151, https://doi.org/10.1175/1520-0493(1982)110<0136: TIOTSI $>2.0 . \mathrm{CO} ; 2$.

Schmetz, J., S. A. Tjemkes, M. Gube, and L. Van de Berg, 1997: Monitoring deep convection and convective overshooting with METEOSAT. Adv. Space Res., 19, 433-441, https:// doi.org/10.1016/S0273-1177(97)00051-3.

Schmit, T. J., and Coauthors, 2015: Rapid Refresh information of significant events: Preparing users for the next generation of geostationary operational satellites. Bull. Amer. Meteor. Soc., 96, 561-576, https://doi.org/10.1175/BAMS-D-13-00210.1.

—, P. Griffith, M. M. Gunshor, J. M. Daniels, S. J. Goodman, and W. J. Lebair, 2017: A closer look at the ABI on the GOES-R series. Bull. Amer. Meteor. Soc., 98, 681-698, https://doi.org/ 10.1175/BAMS-D-15-00230.1.

Schultz, C. J., W. A. Petersen, and L. D. Carey, 2009: Preliminary development and evaluation of lightning jump algorithms for the real-time detection of severe weather. J. Appl. Meteor. Climatol., 48, 2543-2563, https://doi.org/10.1175/ 2009JAMC2237.1.

$\longrightarrow,-$, and —, 2011: Lightning and severe weather: A comparison between total and cloud-to-ground lightning trends. Wea. Forecasting, 26, 744-755, https://doi.org/10.1175/ WAF-D-10-05026.1.

Setvák, M., and Coauthors, 2010: Satellite-observed cold-ringshaped features atop deep convective clouds. Atmos. Res., 97 (1-2), 80-96, https://doi.org/10.1016/j.atmosres.2010.03.009.

—, K. Bedka, D. T. Lindsey, A. Sokol, Z. Charvát, J. Št'ástka, and P. K. Wang, 2013: A-Train observations of deep convective storm tops. Atmos. Res., 123, 229-248, https://doi.org/ 10.1016/j.atmosres.2012.06.020.

Strabala, K. I., S. A. Ackerman, and W. P. Menzel, 1994: Cloud properties inferred from $8-12-\mu \mathrm{m}$ data. J. Appl. Meteor. 33, 212-229, https://doi.org/10.1175/1520-0450(1994)033<0212: $\mathrm{CPIFD}>2.0 . \mathrm{CO} ; 2$.

Thompson, R. L., R. Edwards, J. A. Hart, K. L. Elmore, and P. Markowski, 2003: Close proximity soundings within supercell environments obtained from the Rapid Update Cycle. Wea. Forecasting, 18, 1243-1261, https://doi.org/10.1175/15200434(2003)018<1243:CPSWSE $>2.0$. CO;2.

University of Wyoming, 2017: Upper air soundings archive (subset used: 29 November 2017). Department of Atmospheric Sciences, College of Engineering, accessed 1 December 2017, http://weather.uwyo.edu/upperair/sounding.html.

Vila, D. A., L. A. T. Machado, H. Laurent, and I. Velasco, 2008: Forecast and Tracking the Evolution of Cloud Clusters (ForTraCC) using satellite infrared imagery: Methodology and validation. Wea. Forecasting, 23, 233-245, https://doi.org/ 10.1175/2007WAF2006121.1.

Williams, E. R., B. Boldi, A. Matlin, M. Weber, S. Hodanish, D. Sharp, S. Goodman, R. Raghavan, and D. Buechler, 1999: The behavior of total lightning activity in severe Florida thunderstorms. Atmos. Res., 51, 245-265, https://doi.org/ 10.1016/S0169-8095(99)00011-3.

Witt, A., D. W. Burgess, A. Seimon, J. T. Allen, J. C. Snyder, and H. B. Bluestein, 2018: Rapid-scan radar observations of an Oklahoma tornadic hailstorm producing giant hail. Wea. Forecasting, 33, 1263-1282, https://doi.org/10.1175/ WAF-D-18-0003.1.

Wu, F., X. Cui, and D. L. Zhang, 2018: A lightning-based nowcastwarning approach for short-duration rainfall events: Development and testing over Beijing during the warm seasons of 2006-2007. Atmos. Res., 205, 2-17, https://doi.org/10.1016/ j.atmosres.2018.02.003.

Yost, C. R., and Coauthors, 2018: A prototype method for diagnosing high ice water content probability using satellite imager data. Atmos. Meas. Tech., 11, 1615-1637, https:// doi.org/10.5194/amt-11-1615-2018. 